\title{
Ambient measurements of aromatic and oxidized VOCs by PTR-MS and GC-MS: intercomparison between four instruments in a boreal forest in Finland
}

\author{
M. K. Kajos ${ }^{1}$, P. Rantala ${ }^{1}$, M. Hill ${ }^{2}$, H. Hellén ${ }^{3}$, J. Aalto ${ }^{4}$, J. Patokoski ${ }^{1}$, R. Taipale ${ }^{1}$, C. C. Hoerger ${ }^{2}$, S. Reimann ${ }^{2}$, \\ T. M. Ruuskanen ${ }^{1}$, J. Rinne ${ }^{1,3,5}$, and T. Petäjä ${ }^{1}$ \\ ${ }^{1}$ Department of Physics, University of Helsinki, P.O. Box 64, 00014 Helsinki, Finland \\ ${ }^{2}$ Empa, Swiss Federal Laboratories for Materials Science and Technology, Laboratory for Air Pollution/Environmental \\ Technology, Überlandstr. 129, 8600 Dübendorf, Switzerland \\ ${ }^{3}$ Finnish Meteorological Institute, P.O. Box 503, 00101 Helsinki, Finland \\ ${ }^{4}$ Department of Forest Ecology, Hyytiälä forestry field station, Hyytiäläntie 124, 35500 Korkeakoski, Finland \\ ${ }^{5}$ Department of Geosciences and Geography, University of Helsinki, P.O. Box 64, 00014 Helsinki, Finland
}

Correspondence to: M. K. Kajos (maija.kajos@helsinki.fi)

Received: 13 February 2015 - Published in Atmos. Meas. Tech. Discuss.: 15 April 2015

Revised: 18 September 2015 - Accepted: 28 September 2015 - Published: 22 October 2015

\begin{abstract}
Proton transfer reaction mass spectrometry (PTRMS) and gas chromatography mass spectrometry GC-MS) are commonly used methods for automated in situ measurements of various volatile organic compounds (VOCs) in the atmosphere. In order to investigate the reliability of such measurements, we operated four automated analyzers using their normal field measurement protocol side by side at a boreal forest site. We measured methanol, acetaldehyde, acetone, benzene and toluene by two PTR-MS and two GC-MS instruments. The measurements were conducted in southern Finland between 13 April and 14 May 2012. This paper presents correlations and biases between the concentrations measured using the four instruments. A very good correlation was found for benzene and acetone measurements between all instruments (the mean $R$ value was 0.88 for both compounds), while for acetaldehyde and toluene the correlation was weaker (with a mean $R$ value of 0.50 and 0.62 , respectively). For some compounds, notably for methanol, there were considerable systematic differences in the mixing ratios measured by the different instruments, despite the very good correlation between the instruments (mean $R=0.90$ ). The systematic difference manifests as a difference in the linear regression slope between measurements conducted between instruments, rather than as an offset. This mismatch indicates that the systematic uncertainty in the sensitivity of a given instrument can lead to an uncertainty of 50-100\% in
\end{abstract}

the methanol emissions measured by commonly used methods.

\section{Introduction}

Volatile organic compounds (VOCs) play a crucial role in atmospheric chemistry (Goldstein and Galbally, 2007; Helmig et al., 2014). They participate in tropospheric ozone production (Atkinson and Arey, 1998, 2003), contribute to aerosol particle formation and growth (e.g. Kulmala et al., 2001; Birmili et al., 2003; Tunved et al., 2006; Paasonen et al., 2013; Riipinen et al., 2012; Patoulias et al., 2014), and also affect the oxidation capacity of the atmosphere (e.g. Lelieveld et al., 2008; Rohrer et al., 2014). The large majority of the atmospheric VOCs originate from biogenic sources, but anthropogenic emissions also contribute significantly (Piccot et al., 1992; Guenther et al., 1995, 2012).

In remote and rural locations, biogenic compounds such as isoprene or monoterpenes dominate the concentrations among reactive VOCs. Oxygenated VOCs (OVOCs) are also significant (Guenther et al., 1995, 2012). In urban air, aromatic and oxygenated VOCs make a notable contribution to the total VOC concentrations (e.g. Hellén et al., 2003, 2006; Filella and Peñuelas, 2006; Patokoski et al., 2014). Many of the oxygenated and aromatic VOCs emitted by anthro- 
pogenic sources have long atmospheric lifetimes (from a few days to several weeks) and can be transported thousands of kilometres, making them capable of affecting atmospheric concentrations also in remote locations. These compounds may also have local anthropogenic sources, such as wood combustion or traffic (Hellén et al., 2008; Patokoski et al., 2014).

A variety of models are used to study the atmospheric processes of VOCs. Some simulate the VOC emissions from vegetation (e.g. Grote and Niinemets, 2008; Smolander et al., 2014), others simulate the degradation of VOCs due to their chemical reactions with e.g. atmospheric oxidants (e.g. Jenkin et al., 1997; Apel et al., 2010), and others model their role in new particle formation and other boundary layer and tropospheric processes (e.g. Fast et al., 2006; Holzinger et al., 2007; Makkonen et al., 2012). Many of these models involve dozens of chemical species (including VOCs and trace gases) and complicated chemical and physical processes. Evaluation of these models requires accurate measurements of atmospheric properties, including the VOC concentrations.

Often, VOC concentrations have been measured by collecting samples into canisters or onto adsorbents with subsequent off-line analysis with gas chromatography mass spectrometry (GC-MS) or gas chromatography connected to a flame ionization detector (e.g. Grosjean et al., 1998; Na and Kim, 2001; Hakola et al., 2009; Sauvage et al., 2009). In addition, automated measurements based on both GC techniques and chemical ionization techniques have been developed and utilized (e.g. Lewis et al., 1997; Lindinger et al., 1998; Hakola et al., 2012). Compared to the off-line adsorbent methods, the in situ GC techniques often require only one concentration step, therefore lowering both the background and the detection limits. In addition to lower detection limits, interferences from transport and storage of samples can be avoided.

For automated VOC concentration measurements, in situ GC-MS, proton transfer reaction mass spectrometer (PTRMS) and other chemical ionization-mass spectrometers (CIMS) have been used (e.g. Lindinger et al., 1998; Munson, 2000; de Gouw and Warneke, 2007; Miller et al., 2008; Lopez-Hilfiker et al., 2014). Of these methods, the PTR-MS provides very high time resolution (up to a few $\mathrm{Hz}$ ) and is capable of measuring a wide range of compounds. However, it cannot separate isobaric compounds. GC-MS, on the other hand, can be highly specific for compound identification, but it has lower time resolution (typically $30 \mathrm{~min}$ or more). Both of these methods have been used for measurements in different environments, ranging from highly polluted urban areas to remote locations with low VOC concentrations (e.g. Karl et al., 2003; Rinne et al., 2005; Jordan et al., 2009; Holst et al., 2010; Molina et al., 2010; Hellén et al., 2012b; Hakola et al., 2012).

Typically, a long-term measurement set-up consists of a single analyzer, which is regularly calibrated. Occasionally these instruments are compared with each other either in the laboratory or in the field. The laboratory comparisons are usually conducted by measuring VOC concentrations of a known standard mixture (see e.g. Apel et al., 1994, 1999, 2003, 2008; Slemr et al., 2002; Plass-Dülmer et al., 2006; Rappenglück et al., 2006; Hoerger et al., 2014). However, certain problems in the field measurements cannot be easily identified when only one instrument is used. Therefore, it is important to compare the performance of different real-time instruments in field conditions as well. So far, few studies on field comparison of in situ VOC measurements with PTRMS and GC-MS have been published (de Gouw et al., 2003b, 2004; Kaser et al., 2013; Warneke et al., 2015). de Gouw et al. (2004) studied the correlation between two PTR-MS instruments, Kaser et al. (2013) and Warneke et al. (2015) the correlation between a quadrupole PTR-MS and a PTRTof-MS (PTR-MS with a time-of-flight mass spectrometer) and de Gouw et al. (2003b) the correlation between PTR-MS and GC-MS. Such comparison experiments have not been conducted before in high latitude boreal forest, where the anthropogenic influence on the concentrations is rather small.

The main aim of this study was to evaluate how reliable the in situ measurements of aromatic and oxygenated VOCs are when a single stand-alone instrument is used. This was achieved by comparing VOC concentration measurements of four in situ instruments: two PTR-MSs and two GC-MSs. In order to have a comparison as realistic as possible, no data were rejected from the analysis based on bad correlation of the data between the instruments. Thus, only external reasons have been used to filter the data prior the analysis. This study was part of ACTRIS (Aerosols, Clouds and TRace gases research InfraStructure Network, www.actris.eu, sited on 20 October 2015), which aims to harmonize the European trace gas measurements and to establish a reliable network of continuous long-term measurements. The concentration measurements of three oxygenated VOCs (methanol, acetaldehyde and acetone) and two aromatic VOCs (benzene and toluene) were compared in this study.

\section{Methods}

\subsection{Measurement site}

The measurements were conducted between 13 April and 14 May 2012 at the SMEAR II site (Station for Measuring Forest Ecosystem-Atmosphere Relations, $61^{\circ} 51^{\prime} \mathrm{N}$, $24^{\circ} 17^{\prime}$ E, 181 ma.s.1.) in Hyytiälä, southern Finland. The site is a well-characterized measurement station located in a rural boreal forest dominated by Scots pine (Pinus sylvestris) (for details see Hari and Kulmala, 2005; Ilvesniemi et al., 2010). In addition to Scots pine, there are some Norway spruce (Picea abies) and broadleaved trees such as European aspen (Populus tremula) and birches (Betula sp.) at the site. The annual mean temperature at the site is $3^{\circ} \mathrm{C}$, with the coldest month being January (mean $-9^{\circ} \mathrm{C}$ ) and the warmest July 


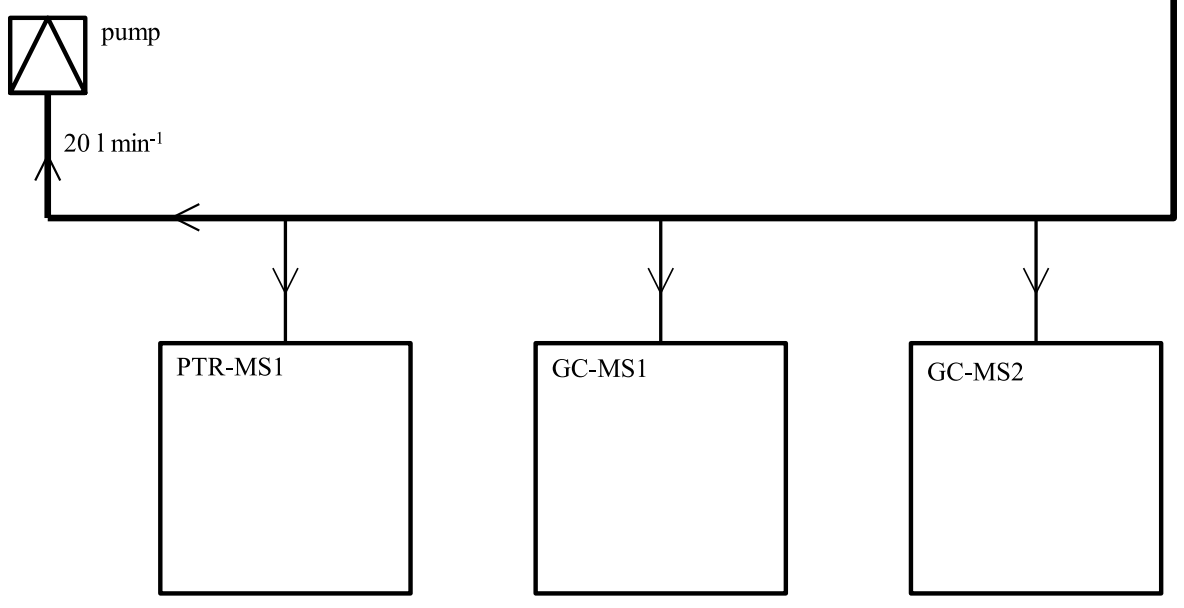

Figure 1. PTR-MS1, GC-MS1 and GC-MS2 shared the same inlet, which was sampling ca. $10 \mathrm{~m}$ above the ground.

(mean $15^{\circ} \mathrm{C}$ ). The annual mean precipitation is $700 \mathrm{~mm}$. The nearest village (Korkeakoski) is about $6 \mathrm{~km}$ away and the nearest big city (Tampere, ca. 200000 inhabitants) is about $50 \mathrm{~km}$ from the site.

The concentrations and sources of oxidized and aromatic VOCs at the site have previously been characterized by Rinne et al. (2005, 2007); Patokoski et al. (2014) and Rantala et al. (2014). Oxidized and aromatic VOCs arrive at the SMEAR II station from both long range and local anthropogenic sources (Liao et al., 2011; Patokoski et al., 2014). OVOCs are also emitted by the vegetation at the site and formed in the oxidation of, for example, monoterpenes (Rinne et al., 2005, 2007; Aaltonen et al., 2013; Aalto et al., 2014; Rantala et al., 2014).

\subsection{The measurement set-up}

The concentrations were measured with two different gas chromatography mass spectrometers (GC-MS1 and GCMS2), and two similar proton transfer reaction quadrupole mass spectrometers, which are hereafter called PTR-MS1 and PTR-MS2. Both PTR-MS instruments were operated by the University of Helsinki, the GC-MS1 was operated by Empa (Switzerland) and the GC-MS2 was operated by the Finnish Meteorological Institute. The two GC-MS instruments and the PTR-MS1 used the same ca. $20 \mathrm{~m}$ long inlet line (Teflon PTFE, $8 \mathrm{~mm}$ id), which sampled $10 \mathrm{~m}$ above the ground with a sample air flow of $20 \mathrm{~L} \mathrm{~min}^{-1}$ (Fig. 1).

The PTR-MS2 is part of the permanent instrumentation of the site and sampled air from a tower about $30 \mathrm{~m}$ away from the common inlet of the other instruments. It measured the ambient atmospheric concentrations during every third hour, as the instrument was used for other measurements during the other $2 \mathrm{~h}$ (Aalto et al., 2014; Rantala et al., 2014). The measurements were obtained at six heights $(4.2,8.4,16.7$, 33.6, 50.4 and $67.2 \mathrm{~m}$ ) for $1 \mathrm{~min}$ at a time at each height. One sampling cycle (MID cycle) lasted for $55 \mathrm{~s}$, during which 27 different compounds were sampled sequentially each with a $2 \mathrm{~s}$ dwell time. Additionally, the primary ion, the first water cluster, oxygen (which is used as a marker for impurities inside the instrument) and mass $m / z 25$ (indicator for detector noise; dark counts) were sampled with dwell times of $0.2 \mathrm{~s}$. The remaining $5 \mathrm{~s}$ were used for switching to the next height. Thus each compound was effectively sampled for $9 \times 2 \mathrm{~s}$ during $1 \mathrm{~h}$. The switching was performed close to the PTR-MS with a solenoid valve (chamber volume of $11 \mu \mathrm{L}$, FKM diaphragm). From each measurement height, the sample air was drawn into the PTR-MS2 via a heated (few degrees above the ambient temperature) $100 \mathrm{~m}$ long inlet line with a constant flow of $45 \mathrm{~L} \mathrm{~min}^{-1}$ (Teflon PTFE, $14 \mathrm{~mm}$ id). In this comparison study, only the measurements taken at $8.4 \mathrm{~m}$ were used. Previously, Kolari et al. (2009) have tested the VOC line losses with a $50 \mathrm{~m}$ long PTFE inlet tubing. The losses were found to be only few percentages, although the inlet flow was only $2 \mathrm{~L} \mathrm{~min}^{-1}$. Therefore, the inlet losses of the PTR-MS2 were assumed to be negligible.

Each instrument measured more than 20 different compounds. However, only methanol, acetaldehyde, acetone, benzene and toluene were measured with both PTR-MS instruments and at least with one GC-MS. As such, they were selected for the comparison study.

\subsection{PTR-MS}

The proton transfer reaction is a chemical ionization technique in which VOCs are ionized by proton transfer from hydronium ions $\left(\mathrm{H}_{3} \mathrm{O}^{+}\right)$. In the PTR-MS (Ionicon Analytik 
$\mathrm{GmbH}$, Austria), the sample air is drawn continuously, without any pretreatment, through the drift tube, where the VOCs of the sample air collide with the $\mathrm{H}_{3} \mathrm{O}^{+}$ions and get ionized if their proton affinity is higher than that of water. From the drift tube the ions are guided to a quadrupole mass spectrometer for mass selection and are then detected by a secondary electron multiplier.

The VOCs gain one proton $\left(\mathrm{H}^{+}\right)$in the proton transfer reaction, thus their mass increases by one atom mass unit (amu) and they are singly charged. As PTR-MS has a mass resolution of one Thomson (Th, i.e. mass-to-charge-ratio), different compounds with the same nominal mass cannot be distinguished. Therefore it is not used for exact identification of the measured compounds (for more details about the instrument, see Lindinger et al., 1998; de Gouw et al., 2003a; Warneke et al., 2003; de Gouw and Warneke, 2007). However, the selectivity of the instrument can be enhanced by varying the $E / N$ (Maleknia et al., 2007; Misztal et al., 2012).

Hydronium primary ions may become hydrated and thus form $\mathrm{H}_{3} \mathrm{O}^{+}\left(\mathrm{H}_{2} \mathrm{O}\right)_{n}$ cluster ions in the drift tube. Cluster formation and fragmentation of the molecules are minimized by applying a suitable electric field $E$, or rather $E / N$ (where $N$ is the density of the buffer gas i.e. air), over the length of the drift tube. As a compromise between minimizing the formation of water clusters and inhibiting the fragmentation of the product ions, $E / N$ values from 110 to 140 Townsend (Td) are typically used. Even with an optimized $E / N$ ratio, a considerable amount of $\mathrm{H}_{3} \mathrm{O}^{+} \mathrm{H}_{2} \mathrm{O}$ clusters are always present in the drift tube when measuring ambient air. Therefore, the measured signals were normalized to $10^{6}$ primary ion counts per second using both $\mathrm{H}_{3} \mathrm{O}^{+}$and $\mathrm{H}_{3} \mathrm{O}^{+} \mathrm{H}_{2} \mathrm{O}$ signals. As benzene and toluene react slowly with the $\mathrm{H}_{3} \mathrm{O}^{+} \mathrm{H}_{2} \mathrm{O}$, only $\mathrm{H}_{3} \mathrm{O}^{+}$ions were considered for the normalization of these two compounds. Heavier water clusters were not taken into account (Warneke et al., 1996, 2001; Tani et al., 2003; de Gouw and Warneke, 2007; Taipale et al., 2008).

The drift tube pressures and voltages of the two PTR-MS instruments were not the same during this experiment, as the instrument parameters were optimized individually. PTRMS1, which is the newest of the two PTR-MS instruments, was set to have a drift tube pressure of 2.2 mbar and voltage of $600 \mathrm{~V}$, while PTR-MS2 was ran with a drift pressure and voltage of $2.0 \mathrm{mbar}$ and of $510 \mathrm{~V}$, respectively. Therefore the $E / N$ of PTR-MS1 was $136 \mathrm{Td}$, and that of PTRMS2 was $120 \mathrm{Td}$. Possible changes in the drift tube pressures were taken into account by normalizing the drift pressures to 2 mbar. Exactly the same procedures were applied for the calibration and volume mixing ratio (VMR) calculation for both PTR-MS instruments. Each measured compound was sampled with a $2 \mathrm{~s}$ dwell time, while the dwell time of the $\mathrm{H}_{3} \mathrm{O}^{+}$and $\mathrm{H}_{3} \mathrm{O}^{+} \mathrm{H}_{2} \mathrm{O}$ was $0.2 \mathrm{~s}$ in case of both PTR-MS instruments.

A thorough description of the VMR calculation procedure is given by Taipale et al. (2008). Thus, only a brief summary is given here. To convert the measured counts per second (cps) signals to concentrations (ppb, parts per billion, $10^{-9}$ ), one needs to know (a) the signals of the primary ions $\mathrm{H}_{3} \mathrm{O}^{+}$ and $\mathrm{H}_{3} \mathrm{O}^{+} \mathrm{H}_{2} \mathrm{O}$, (b) the instrumental background signals and (c) the sensitivities for all the measured compounds.

a. The signals of primary ions are measured during each measurement cycle, but in order to maximize the lifetime of the detector, the count rates of the primary ions were measured at the $m / z 21$ and $m / z$ 39, corresponding to the isotopes, $\mathrm{H}_{3}^{18} \mathrm{O}^{+}$and $\mathrm{H}_{3}^{18} \mathrm{O}^{+}\left(\mathrm{H}_{2} \mathrm{O}\right)$, respectively. The abundance of the primary ions is not constant, but can vary substantially over the course of a few days and sometimes even within hours. This variation is taken into account by normalizing the VOC count rates and sensitivities with pre-averaged ( 5 min running mean) primary ion signal/signals (Taipale et al., 2008).

b. Instrumental background signal can be caused by, for example, desorption of impurities inside the instrument or inside the inlet system, manifesting as a notable offset in the count rates of many of the VOCs (Steinbacher et al., 2004). These background signals are taken into account, by regular measurement of VOC free air (hereafter "zero air"). The background signals are then subtracted from the measured signals. During this campaign, zero air was measured every second hour with PTR-MS1 and every third hour with PTR-MS2. The zero air, was produced by pumping ambient air through a catalytic converter (Parker Balston zero air generator HPZA-3500, USA and Parker ChromGas Zero Air Generator 3501, USA).

c. In order to quantify the sensitivities for the measured compounds, calibrations were done using an automatic calibration method using mixing units. These mixing units dilute a standard gas flow of ca. $6 \mathrm{~mL} \mathrm{~min}^{-1}$ to a zero air flow of ca. $1000 \mathrm{~mL} \mathrm{~min}^{-1}$. Both instruments had their own identical mixing units, each of which consist of a $1 \mathrm{~L}$ ( 40 bar) standard gas cylinder and two mass flow controllers, which regulate the standard gas and the zero air flow (Bürkert 8710-10, and Bürkert 8710-03, Bürkert GmbH Germany, respectively) automatically. Previously Taipale et al. (2008) calibrated the instrument by diluting $50-120 \mathrm{~mL} \mathrm{~min}^{-1}$ of standard gas to 1000-3000 $\mathrm{mL} \mathrm{min}^{-1}$ of zero air, which was done with a set-up that uses a $60 \mathrm{~L}$ standard gas bottle (with an initial pressure of 140 bar). The flow is regulated manually with a pressure regulator and is fine-tuned with a needle valve. Hereafter this calibration method is referred to as "manual calibration". The comparability of the manual and the automatic calibration methods was studied in separate calibration method comparison tests, which were performed after the campaign for both PTR-MS instruments.

Both instruments were calibrated three times during the campaign, using the same gas standard mixture (Apel- 
Riemer Environmental Inc., CO, USA), consisting of 13 different VOCs including methanol, acetaldehyde, acetone, benzene and toluene in the range of $0.84-1.14 \mathrm{ppb}$.

The detection limits of the PTR-MS instruments were calculated as 3 times the $\mathrm{SD}(3 \sigma)$ of the background measurement. This background signal varies over time, leading to changes in the detection limits. Possible changes in background signals were taken into account by calculating detection limits separately for all calibration periods of the PTRMS instruments.

\subsection{GC-MS instruments}

The analysis of VOCs with gas chromatographic techniques relies on the separation of the VOC species in a chromatographic column. Traditionally, the samples have been collected into a canister or adsorbent tubes and analyzed off-line in the laboratory. With more recent in situ GC-MS systems, the samples are collected directly into adsorbent traps at the measurements site, from which they are desorbed by heating the trap in the gas chromatograph. After separating the compounds by their retention times in the chromatographic columns, they are ionized by electron ionization and detected individually with a quadrupole mass spectrometer.

\subsubsection{GC-MS1}

The instrumental set-up of the adsorption-desorption system coupled to a gas chromatograph-mass spectrometer (GCMS1) is described in detail by Legreid et al. (2007, 2008). Briefly, every $46 \mathrm{~min}$ a $12 \mathrm{~min}$ air sample of $350 \mathrm{~mL}$ was collected. VOCs were collected into a two-stage adsorbent system connected to a GC-MS (Agilent 6890-5973N, Agilent Technologies, CA, USA). The water removal was performed on the sampling trap ( $0.6 \mathrm{~g}$ of Hayesep D, Supelco, Switzerland) at room temperature. The hydrophobic nature of the adsorbent material allowed most of the water to pass through the trap, and the remaining humidity was removed by dry helium flushing. Thereafter, the compounds were refocused on a microtrap (14 mg of Hayesep D, Supelco, Switzerland) at $-40^{\circ} \mathrm{C}$ to improve the separation of the compounds on the analytical column. The compounds were rapidly desorbed from the trap $\left(180^{\circ} \mathrm{C}\right)$ and transferred to the GC. The chromatographic separation was performed on a $25 \mathrm{~m} \times 0.32 \mu \mathrm{m}$ CP-Porabond U column (Varian Inc., CA, USA) with $7 \mu \mathrm{m}$ film thickness. Individual compounds were detected by operating the MS in selected ion monitoring (SIM) mode, for an improved signal-to-noise ratio. The compounds were identified by their mass spectra and quantified using a 24 compound OVOC standard gas mixture in the range of 350$450 \mathrm{ppb}$ (Apel-Riemer Environmental Inc., CO, USA), and a 30-compound VOCs standard gas mixture in the range of 1$10 \mathrm{ppb}$ (National Physical Laboratory, UK). Calibration was performed once every $23 \mathrm{~h}$ by filling a calibrated sample loop
$(127 \mu \mathrm{L})$, which was flushed with helium into the adsorbent trap.

Methanol was only recovered at $45 \%$, and this was corrected for the measurement campaign. The detection limit for each compound was calculated as 3 times the SD of five zero air samples.

\subsubsection{GC-MS2}

Measurements of GC-MS2 were conducted using an in situ thermal desorption unit (Markes' Unity, Markes International Ltd, UK) with a gas chromatograph (Agilent 7890A, Agilent Technologies, CA, USA) and a mass spectrometer (Agilent 5975N, Agilent Technologies, CA, USA). The column used was the $60 \mathrm{~m}$ long DB-5 with an inner diameter of $0.235 \mathrm{~mm}$ and a film thickness of $1 \mu \mathrm{m}$. One $60 \mathrm{~min}$ sample was taken every other hour. Ozone was removed by a heated stainless steel inlet (temp. $150^{\circ} \mathrm{C}$, length $1 \mathrm{~m}$, o.d. $1 / 8$ inch, flow $0.8 \mathrm{~L} \mathrm{~min}^{-1}$; Hellén et al., 2012a). Due to the gradually decreasing ozone removal capacity, the ozone removal inlet was changed every second week. VOCs in $30 \mathrm{~mL} \mathrm{~min}^{-1}$ subsample were collected directly into the microtrap (U-T15ATA-2S, Markes International Ltd, UK) of the thermal desorption unit. Water was removed by keeping the hydrophobic cold trap at $15^{\circ} \mathrm{C}$. For calibration, a gaseous standard mixture of 17 VOCs each at a concentration of $2 \mathrm{ppb}$ (National Physical Laboratory, UK) was run after every 50th sample. The limits of detection, calculated as 3 times the SD of the zero levels, were $215 \mathrm{ppt}$ for acetone, $34 \mathrm{ppt}$ for benzene and $9 \mathrm{ppt}$ for toluene.

\subsection{Uncertainties of the instruments}

The uncertainties of the VOC concentrations measured by a PTR-MS or a GC-MS are affected by several factors. The total uncertainty $(\Delta U)$ can be estimated by using the Gaussian propagation of uncertainty if the uncertainties of different steps of the data processing are known. In the following chapters, the total uncertainty calculations of PTR-MS instruments and the GC-MS instruments are described separately. One should keep in mind that, in addition to the total (random) uncertainty described in this chapter, the measurements may still have additional constant error (bias) of unknown magnitude, which can bias the measured concentrations.

\subsubsection{Uncertainty of the PTR-MS measurement}

The total measurement uncertainty of PTR-MS consists of two parts; the uncertainty of the signal $\left(\Delta U_{\text {signal }}\right)$ and the uncertainty of the calibration $\left(\Delta U_{\text {calibration }}\right)$ :

$\Delta U^{2}=\Delta U_{\text {signal }}^{2}+\Delta U_{\text {calibration }}^{2}$.

The measured signal and the background signal are normalized with the primary ion signal for the VMR calculation. 
The normalized background signal $\left(I_{\text {zero }}\right)$ is subtracted from the normalized measured signal $\left(I_{\text {meas }}\right)$ and this backgroundcorrected normalized signal is divided by the normalized sensitivity, $S$, which is obtained from the calibration. Thus,

$\mathrm{VMR}=\frac{I_{\text {meas }}-I_{\text {zero }}}{S}$.

The uncertainty of the signal in Eq. (1) contains the uncertainties of the measured signal $\left(\Delta U_{\text {meas }}\right)$ and the background signal $\left(\Delta U_{\text {zero }}\right)$,

$\Delta U_{\text {signal }}^{2}=\Delta U_{\text {meas }}^{2}+\Delta U_{\text {zero }}^{2}$.

The measured count rates (cps, counts per second) and the count rates of the zero measurement were converted to counts ( $I_{\text {counts }}$ and $\left.I_{\text {counts, zero }}\right)$ by multiplying with the dwell time ( $2 \mathrm{~s}$ for each molecule). As the PTR-MS statistics follow the Poisson distribution, the uncertainty of a single measurement point $\left(\Delta I_{\text {meas }}\right)$ is simply the square root of the counts $\left(\sqrt{I_{\text {counts }}}\right)$. One background measurement consisted of 11 measurement points, from which the average background signal was derived. The nearest background value was subtracted from each individual ambient measurement point. The uncertainty of one background measurement $\left(\Delta I_{\text {zero }}\right)$ was calculated as the SD of the 11 measurement points.

In order to normalize $I_{\text {counts }}$ and $I_{\text {counts, zero }}$ they both need to be divided by the primary ion $\left(\mathrm{H}_{3} \mathrm{O}^{+}\right.$and $\left.\mathrm{H}_{3} \mathrm{O}^{+} \mathrm{H}_{2} \mathrm{O}\right)$ counts, which are obtained by multiplying the count rates of the primary ions by their dwell times. However, the primary ion signal is much higher than the measured signals and the zero signals. In addition, it remained approximately constant during the time when the $I_{\text {counts }}$ and the nearest $I_{\text {counts, zero }}$ were measured. Thus, the primary ion signal uncertainty is less than $1 \%$ and it was thus neglected.

The uncertainty of the calibration $\left(\Delta U_{\text {cal }}\right)$ is due to the uncertainty of the sensitivity $(\Delta S)$ and the uncertainty of the calibration gas standard $\left(\Delta U_{\text {stdgas }}\right)$ due to uncertainty of the concentrations in the calibration gas standard $\left(\Delta \chi_{\text {cal }}\right)$ :

$\Delta U_{\text {calibration }}^{2}=\Delta U_{\text {cal }}^{2}+\Delta U_{\text {stdgas }}^{2}$.

PTR-MS sensitivity for a certain compound is determined by calibrating the instrument with a known concentration of that compound. When the ratio of the sensitivity and its uncertainty is assumed to be constant, the sensitivity's uncertainty can be determined from the SD of a series of calibrations, performed using the same instrument settings. The laboratory tests for the similarity of the two calibration methods were done under the same instrument conditions, making the relative sensitivity uncertainty $(\Delta S)$ obtainable from those measurements. The manufacturer of the calibration gas standard reports relative uncertainty ( $\left.\Delta \chi_{\mathrm{cal}}\right)$, of $\pm 5 \%$ for the concentration of each VOC compound in the calibration gas mixture.

By combining Eqs. (1)-(4) and using the Gaussian propagation of error, the total uncertainty of PTR-MS for one mea- surement point is

$$
\frac{\Delta U=\sqrt{\left(\frac{\Delta I_{\text {meas }}}{I_{\text {meas }}-I_{\text {zero }}} \mathrm{VMR}\right)^{2}+\left(\frac{\Delta I_{\text {zero }}}{I_{\text {meas }}-I_{\text {zero }}} \mathrm{VMR}\right)^{2}+}}{(\Delta S \mathrm{VMR})^{2}+\left(\Delta \chi_{\text {cal }} \mathrm{VMR}\right)^{2}} .
$$

For $N$ measurement points, the total relative uncertainty can be calculated as

$$
\begin{aligned}
& \Delta U_{\text {rel }}=\frac{1}{N \overline{\mathrm{VMR}}} \sqrt{\sum_{i=1}^{N}\left(\frac{\Delta I_{i, \text { meas }}}{I_{i, \text { meas }}-I_{i, \text { zero }}} \mathrm{VMRi}_{i}\right)^{2}+} \\
& \overline{\sum_{i=1}^{N}\left(\frac{\Delta I_{i, \text { zero }}}{I_{i, \text { meas }}-I_{i, \text { zero }}} \mathrm{VMRi}_{i}\right)^{2}+\left(\sum_{i=1}^{N} \Delta S \mathrm{VMRi}_{i}\right)^{2}+} \\
& \overline{\left(\sum_{i=1}^{N} \Delta \chi_{\mathrm{cal}} \mathrm{VMR}_{i}\right)^{2}}
\end{aligned}
$$

where $\overline{\mathrm{VMR}}$ is the average volume mixing ratio of $N$ measurements. Because different measurement points are independent, the total precision can be calculated using the Gaussian propagation of error. However, as $\Delta S$ and $\Delta \chi_{\text {cal }}$ are constant, the total systematic error is calculated as a linear sum of the errors of single measurement points.

Total uncertainties of $1 \mathrm{~h}$ were calculated for PTR-MS1 and PTR-MS2, as the data comparison was mostly done using 1-hour averages.

\subsubsection{Uncertainty of the GC-MS1 measurement}

The total uncertainty is divided into two components: precision $\left(\Delta U_{\text {precision }}\right)$ and systematic error $\left(\Delta U_{\text {systematic }}\right)$ :

$\Delta U^{2}=\Delta U_{\text {precision }}^{2}+\Delta U_{\text {systematic }}^{2}$.

The precision is calculated as

$\Delta U_{\text {prec }}=\frac{1}{3} \mathrm{DL}+\chi \sigma_{\text {sample, rel }}$,

where DL is the detection limit, $\chi$ is the mole fraction (peak area) of the considered peak and $\sigma_{\text {sample, rel }}$ is the relative SD of the sample. The first term of Eq. (8) considers the resolution of the instrument (e.g. background noise) and the second term considers the repeatability of the measurements. For low mole fractions the first term dominates, while for high mole fractions the second term dominates.

The systematic error of GC-MS1 includes the following: the error due to uncertainty of the calibration standard's mole fractions $\left(\Delta \chi_{\text {cal }}\right)$, systematic integration errors due to peak overlay or poor baseline separation $\left(\Delta \chi_{\text {int }}\right)$, systematic errors due to blank correction $\left(\Delta \chi_{\text {blank }}\right)$, and potential further instrument problems $\left(\Delta \chi_{\text {instrument }}\right)$ caused by, for example, 
Table 1. Total relative uncertainties of the measured compounds for all the instruments. The uncertainty values of PTR-MS1 and PTRMS2 are averages of hourly total uncertainties. For GC-MS1 and GC-MS2, the total uncertainties are for one measurement point.

\begin{tabular}{lrrrr}
\hline compound & $\begin{array}{r}\text { PTR-MS1 } \\
{[\%]}\end{array}$ & $\begin{array}{r}\text { PTR-MS2 } \\
{[\%]}\end{array}$ & $\begin{array}{r}\text { GC-MS1 } \\
{[\%]}\end{array}$ & $\begin{array}{r}\text { GC-MS2 } \\
{[\%]}\end{array}$ \\
\hline methanol & 61 & 21 & 15 & - \\
acetaldehyde & 11 & 11 & 28 & - \\
acetone & 13 & 8 & 23 & 17 \\
benzene & 8 & 12 & 14 & 4 \\
toluene & 2 & 45 & 14 & 5 \\
\hline
\end{tabular}

sampling line artefacts, possible non-linearity of the detector or changes of split flow rates. Hence, the systematic error is

$\Delta U_{\text {systematic }}^{2}=\Delta \chi_{\text {cal }}^{2}+\Delta \chi_{\text {int }}^{2}+\Delta \chi_{\text {blank }}^{2}+\Delta \chi_{\text {instrument }}^{2}$.

The systematic error due to the calibration gas uncertainty $\left(\Delta \chi_{\text {cal }}\right)$ is calculated as

$\Delta \chi_{\text {cal }}=\frac{A_{\text {sample }} V_{\text {cal }}}{A_{\text {cal }} V_{\text {sample }}} \delta \chi_{\text {cal }}$,

where $A_{\text {sample }}$ is the peak area of the sample measurement, $A_{\text {cal }}$ the peak area of the calibration standard measurement, $V_{\text {sample }}$ the volume of sample, $V_{\text {cal }}$ the sample volume of the calibration standard, and $\delta \chi_{\text {cal }}$ certified standard uncertainty of calibration standard and potential drift of the calibration standard.

The systematic integration error $\left(\Delta \chi_{\text {int }}\right)$ is

$\Delta \chi_{\text {int }}^{2}=\left(\frac{f_{\text {cal }}}{V_{\text {sample }}} \delta A_{\text {sample }}\right)^{2}+\left(\frac{A_{\text {sample }} V_{\text {cal }} \chi_{\text {cal }}}{V_{\text {sample }} A_{\text {cal }}^{2}} \delta A_{\text {cal }}\right)^{2}$

with $f_{\text {cal }}=\frac{V_{\text {cal }} \chi_{\text {cal }}}{A_{\text {cal }}}$,

where $\delta A_{\text {cal }}$ is the relative error in peak area due to integration of the calibration measurement, $\delta A_{\text {sample }}$ is the integration error of the sample measurement and $\chi_{\text {cal }}$ is the mole fraction of the calibration standard peak. If a blank correction has to be applied, the error of this correction is described as the deviation from the mean blank value:

$\Delta \chi_{\text {blank }}=\sigma_{\text {blank }} \frac{1}{\sqrt{N-1}}$,

where $\sigma_{\text {blank }}$ is the SD of the zero gas measurements and $N$ is the number of those zero-gas measurements. For more details on the uncertainty calculation of GC-MS1 see Hoerger et al. (2014).

The precision of acetone, acetaldehyde, benzene, and toluene was around $5 \%$, whereas the precision for methanol was $10 \%$. The total expanded uncertainty was around $15 \%$ for acetone, benzene, and toluene, $23 \%$ for acetaldehyde, and $28 \%$ for methanol (Table 1). These values are in good agreement with previous studies (Apel et al., 2008).

\subsubsection{Uncertainty of the GC-MS2 measurement}

Total uncertainty $(\Delta U)$ of the GC-MS2 is calculated as

$\Delta U^{2}=\Delta \chi_{\text {cal }}^{2}+\Delta \chi_{\text {blank }}^{2}+\Delta \chi_{\text {analysis }}^{2}+\Delta \chi_{\text {flow }}^{2}$,

where $\Delta \chi_{\text {cal }}$ is the uncertainty of the standard preparation, $\Delta \chi_{\text {blank }}$ is the uncertainty of the blank level, $\Delta \chi_{\text {analysis }}$ is the uncertainty of the analysis and $\Delta \chi_{\text {flow }}$ is the uncertainty of the sample flow. Uncertainties of the standard preparation and sample flow were given, respectively, by the manufacturers of the calibration gas standard and the mass flow controller. The blank level uncertainty was calculated as the SD of all blank values measured during the campaign. The uncertainty of the analysis was obtained from the relative SD of the analysis of 15 identical calibration standards. Analytical uncertainties calculated from partial uncertainties at a concentration level of $2 \mathrm{ppb}$ were $17 \%$ for acetone, $4 \%$ for benzene and $5 \%$ for toluene.

\subsection{Data processing}

The concentrations measured with different instruments had temporal discrepancies, as all of the instruments had different sampling intervals and data integration times. PTR-MS1 measured several compounds sequentially, each with a dwell time of $2 \mathrm{~s}$, which lead to a 1 min time-resolution. The ambient concentrations were measured 43 times during each hour, after which the background was sampled 11 times. PTRMS2 measured ambient concentrations every third hour, during which each of the six measurement heights were sampled every sixth minute. Also, PTR-MS2 measured background during the same hour as the ambient concentrations were measured. Each measurement height was sampled eight times within the $1 \mathrm{~h}$ averaging period, followed by 11 background samples. In this analysis, the concentrations measured at $8.4 \mathrm{~m}$ height were used. GC-MS1 collected a sample for $12 \mathrm{~min}$, after which the sample was analysed for $34 \mathrm{~min}$. Thus, a concentration value was recorded every $46 \mathrm{~min}$. GCMS2 sampled for 60 min during every second hour and analysed the sample in between the sampling times.

In order to make the instrument comparison as consistent as possible, the measurements by the two PTR-MS instruments were averaged for the same time periods with each other and with the GC-MS instrument whenever possible. For the comparison between the two PTR-MS instruments and PTR-MS1 and GC-MS2, hourly averages were used. For the comparison between PTR-MS1 and GC-MS1, PTR-MS1 data were averaged for the same 12 min time periods when GC-MS1 samples were taken.

The detection limits of all the instruments were determined as 3 times the SD of the instrument noise (i.e. the zero air sample concentration). Values below the detection limits were removed from the GC-MS data. When hourly or 12 min average values were calculated from PTR-MS data, the averages were calculated for all data points. If an average 
Table 2. Uncertainty values for a single measurement point for PTR-MS1 and PTR-MS2. Uncertainty of the signal statistics $\left(\Delta U_{\text {rel, }}\right.$ sig $)$ includes both uncertainties of the measured signal and the background signal. $\Delta U_{\text {rel, cal }}$ is the relative uncertainty of the sensitivity. The total uncertainty, $\Delta U_{\text {rel }}$, includes an additional $5 \%$, the concentration uncertainty of the calibration gas standard, which was constant for all the compounds. All the values are presented in percentages.

\begin{tabular}{lrrr|rrr}
\hline & \multicolumn{3}{c|}{ PTR-MS1 } & \multicolumn{3}{c}{ PTR-MS2 } \\
\cline { 2 - 7 } compound & $\Delta U_{\text {rel, sig }}$ & $\Delta U_{\text {rel, cal }}$ & $\Delta U_{\text {rel }}$ & $\Delta U_{\text {rel, sig }}$ & $\Delta U_{\text {rel, cal }}$ & $\Delta U_{\text {rel }}$ \\
\hline methanol & $<1$ & 63 & 63 & 12 & 25 & 31 \\
acetaldehyde & $<1$ & 10 & 11 & 11 & 5 & 24 \\
acetone & $<1$ & 12 & 14 & 3 & 4 & 10 \\
benzene & 1 & 6 & 8 & 12 & 3 & 26 \\
toluene & 1 & 9 & 10 & 31 & 2 & 65 \\
\hline
\end{tabular}

value was below the detection limit, it was removed from further analysis. Data points below the detection limits were not removed before average value calculation, in order to avoid biasing the average.

\subsection{Laboratory test of the PTR-MS calibration systems}

The sensitivities and uncertainties of sensitivities of the two PTR-MS instruments and the performance of the two different calibration methods were evaluated in separate laboratory tests after the field campaign. The laboratory tests were done by performing a series of calibrations with both automatic and manual calibration methods, while keeping all instrument parameters constant. The same calibration tests were performed separately for both PTR-MS instruments. A constant ratio was assumed for the sensitivity and its uncertainty, thus the latter was determined as the SD of the sensitivity measurement series. The results of the calibration tests are presented in Table A1 in the Appendix.

\section{Results}

\subsection{PTR-MS sensitivities}

Generally, the PTR-MS2 had higher sensitivity than the PTRMS1 for all compounds except isoprene. This was particularly the case for the larger molecules (xylenes, trimethylbenzene, naphthalene and $\alpha$-pinene). The higher sensitivity of PTR-MS2 can be partly explained by the instruments having different $E / N$ values, but the main reasons are the different transmission efficiencies within the two instruments.

For most of the compounds, calculated sensitivities of both automatic and manual calibration methods agreed within the sensitivity uncertainty (Table A1). However, for methanol and methyl vinyl ketone, the sensitivities obtained with the two different methods were divergent for both PTR-MS instruments. For acetonitrile, the two calibration methods resulted in different sensitivities in the case of PTR-MS2. For naphthalene, the two methods resulted in different sensitivities in the case of PTR-MS1.
The sensitivity uncertainties of both calibration methods were lower for PTR-MS2. Regarding the manual calibration method, the pump used to generate zero air for the calibration of PTR-MS1 caused some fluctuation to the zero air flow and thus increased the sensitivity variation (i.e. the SD) between different calibrations. The uncertainty of sensitivity for methanol obtained with the automatic calibration system was clearly higher than the uncertainties for all other compounds, $63 \%$ for PTR-MS1 and $25 \%$ for PTR-MS2.

Methanol calibration is difficult due to its strong interaction with metal surfaces, as in mass flow controllers (de Gouw et al., 2003a). Higher apparent methanol sensitivities and sensitivity uncertainties were obtained with the manual calibration method, which contains fewer metal surfaces than the automatic calibration system. It had also been used for a longer time, and the surfaces of the pressure regulator and needle valve were evidently more saturated with methanol than the metal surfaces of the mixing units that were used for the automatic calibration.

In the case of PTR-MS1, the sensitivity uncertainties were higher than the uncertainties of the signal statistics or the concentration uncertainty of the calibration gas standard (Table 2). The signal uncertainty was $1 \%$ or less for all compounds for PTR-MS1, while for PTR-MS2 the signal uncertainties were higher, and contributed to the total uncertainty. The higher signal uncertainties of PTR-MS2 were due to the rather low sampling frequency (eight samples per hour) of the PTR-MS2. The signal uncertainty of toluene was particularly high $(65 \%)$.

\subsection{Total uncertainties of the concentration measurements}

The total uncertainties of all instruments were below $30 \%$, with the exception of the methanol uncertainty of PTR-MS1 and the toluene uncertainty of PTR-MS2 (Table 1). GCMS2 had low total uncertainties for benzene and toluene concentrations. However, uncertainties of GC-MS2 were determined at a concentration of $2 \mathrm{ppb}$, which is higher than the concentrations measured for benzene and toluene during 

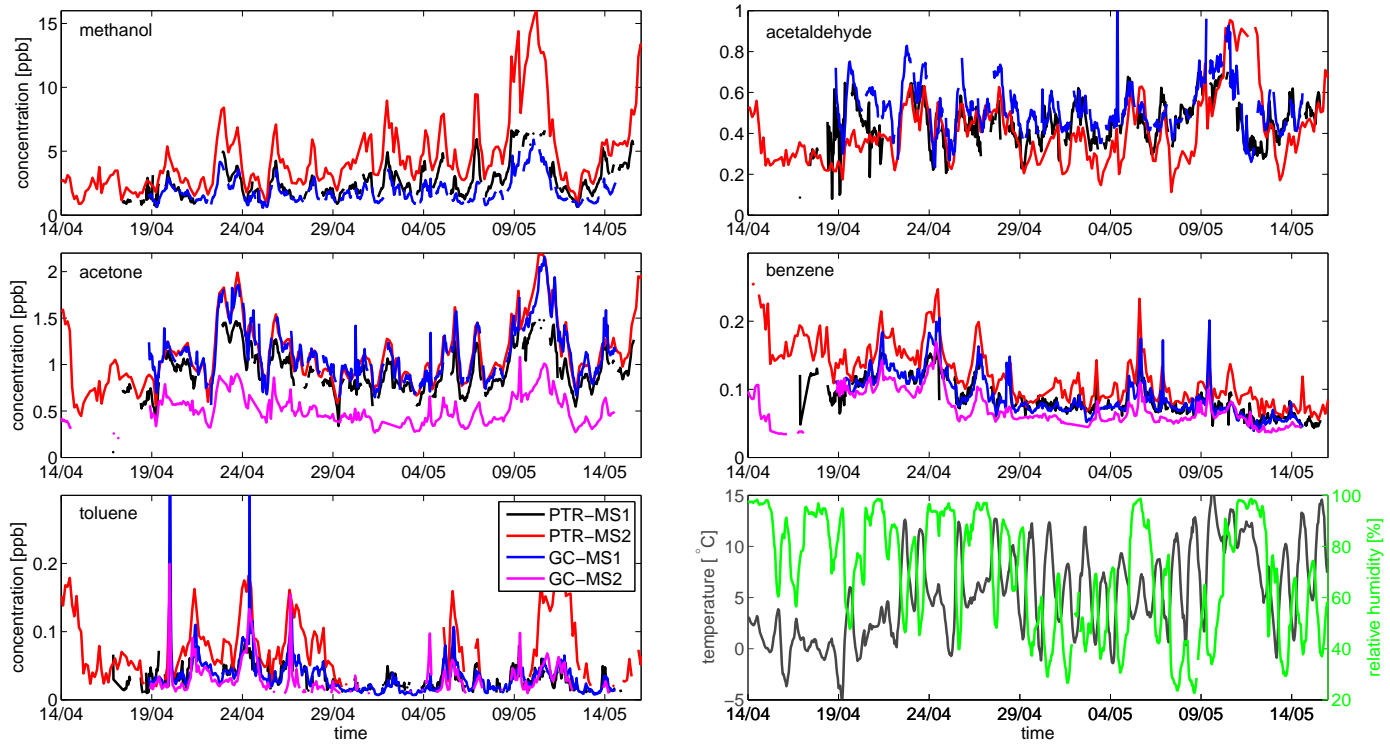

Figure 2. Concentrations of methanol, acetaldehyde, acetone, benzene and toluene measured with PTR-MS1, PTR-MS2, GC-MS1 and GCMS2 and ambient temperature and relative humidity during the measurement campaign. Hourly averages were calculated for the PTR-MS instruments. For the GC-MS instruments, all data are shown.

this campaign. Thus, the uncertainty values of benzene and toluene are too low. GC-MS1 and the two PTR-MS instruments had somewhat similar uncertainties for benzene. However, the PTR-MS1 uncertainty for toluene concentration was only $2 \%$ while the PTR-MS2 uncertainty for toluene was $45 \%$. The high total toluene uncertainty of PTR-MS2 follows from the high signal uncertainty.

For acetone and acetaldehyde, the concentration uncertainties of the PTR-MS instruments were lower than those of the GC-MS instruments. In the case of methanol, GC-MS1 and PTR-MS2 had similar uncertainties, while PTR-MS1 had a very high total uncertainty $(61 \%)$. The high methanol uncertainty of PTR-MS1 was a consequence of the high sensitivity uncertainty.

\subsection{General features of the ambient data}

The time series of methanol, acetaldehyde, acetone, benzene and toluene concentrations measured with all instruments are presented in Fig. 2. All instruments measured similar concentration patterns for methanol, acetone and benzene. Figure 3 also reveals similar patterns in daily median concentrations. However, both figures show systematic differences between the instruments.

The highest concentrations of methanol, acetone and benzene were measured with PTR-MS2, while GC-MS2 measured systematically lower concentrations of acetone and benzene than the other three instruments. In the case of acetone, the lower concentrations measured by GCMS2 were probably due to the $60 \mathrm{~min}$ sampling time. This may have been too long, leading to break through of acetone in the mi- crotrap. Consequently, the absolute values of the GC-MS2 were underestimations, but the concentrations trends were still observed.

The measured acetaldehyde concentrations had fairly small temporal variation. Additionally, the concentration trends measured with the three instruments are divergent until the beginning of May. After the 1 May, PTR-MS1 and GC-MS1 measurements agree rather well.

Toluene concentrations were mostly below the detection limits of the PTR-MS instruments. This is clearly visible in Fig. 2, where the toluene time series of PTR-MS1 and PTRMS2 consists of fewer points than the time series of the other compounds. The daily median concentrations measured by PTR-MS1, however, show a trend similar to GC-MS1 and GC-MS2.

The different location of the PTR-MS2 inlet could partly explain the higher concentrations observed for methanol, acetaldehyde and acetone. Acetaldehyde and acetone are formed in the oxidation of, for example, monoterpenes and methylbutenol (Kesselmeier et al., 1997; Goldstein and Schade, 2000; Villanueva-Fierro et al., 2004; Millet et al., 2010) and acetaldehyde, acetone and methanol are emitted by the vegetation at the site (Rinne et al., 2007; Aalto et al., 2014; Rantala et al., 2014). The relative contribution of local biogenic sources to the total atmospheric concentrations of methanol and acetone is likely to be low as these compounds have relatively long atmospheric lifetimes $(4,16$ and 33 days, respectively, in the spring) and high background concentrations originating from distant sources (Patokoski et al., 2014). As such, their concentrations are likely to have relatively low small-scale spatial variability at the site. 

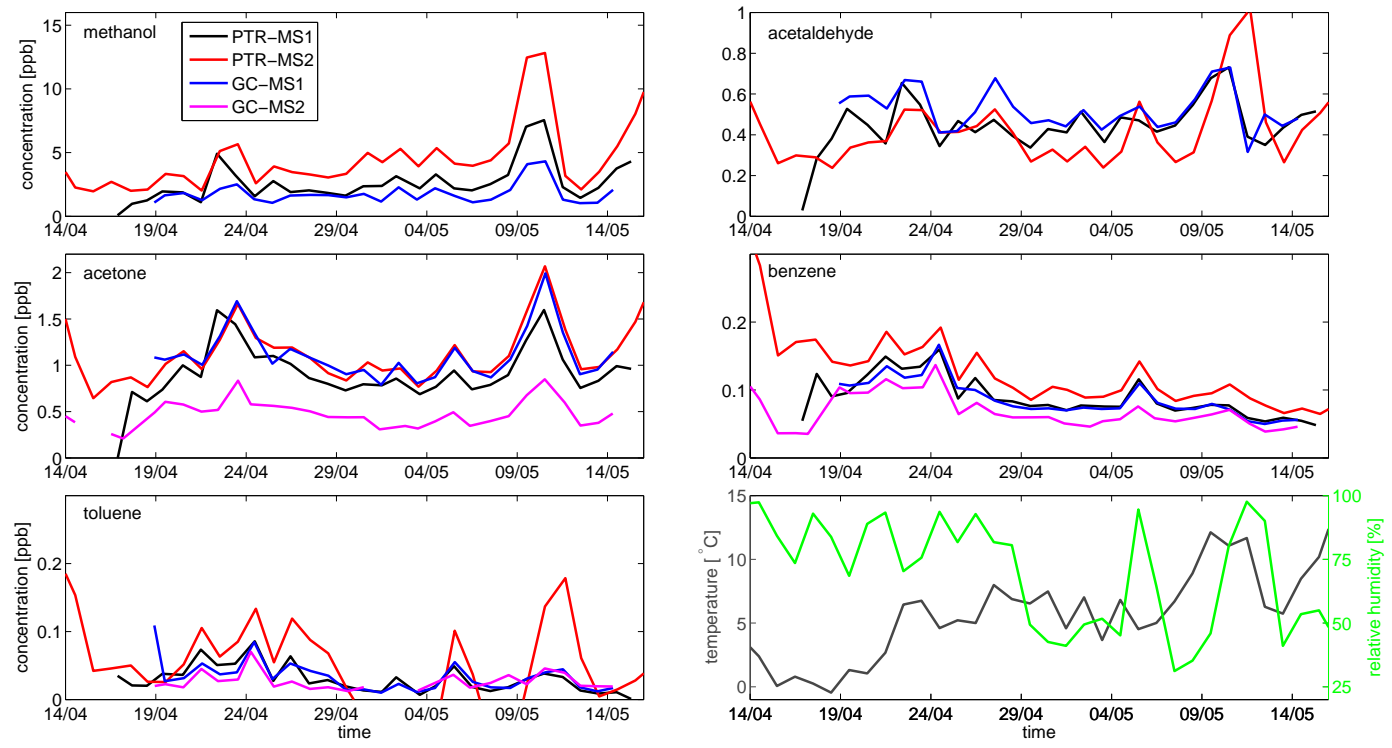

Figure 3. Daily median temperature, relative humidity and concentrations of compounds measured with PTR-MS1, PTR-MS2, GC-MS1 and GC-MS2 during the measurement campaign.

Benzene and toluene observed at the SMEAR II site originate from local traffic and small-scale wood combustion, as well as from distant anthropogenic sources (Hakola et al., 2003; Hellén et al., 2006; Patokoski et al., 2014). Occasional traffic near the measurement site may have caused short pollution events and concentration differences between the two inlets. However, these episodes were rare and their influence on the hourly average values was probably low. There should not be considerable spatial variation in benzene and toluene concentrations at the site, as a majority of both compounds originate from anthropogenic sources outside of the measurement site, and have relatively long atmospheric lifetimes (Hakola et al., 2003; Hellén et al., 2006; Patokoski et al., 2014).

Toluene concentrations were mostly below the detection limits of the PTR-MSs. This is clearly visible in Fig. 2, where the toluene time series of PTR-MS1 and PTR-MS2 consists of fewer points than the time series of the other compounds. The daily median concentrations measured by PTR-MS1, however, show a trend similar to GC-MS1 and GC-MS2.

\subsection{Differences between the instruments by compound}

In order to analyze in more detail how consistent the concentration measurements were, box plots representing the medians and quartiles were drawn for all compounds (Fig. 4). The concentration ranges of different instruments were determined from the box plots. Accordingly, concentration range is hereafter defined as the range between 25 and 75 percentile.

Correlations between different instruments were studied using scatter plots and by calculating Pearson's correlation coefficients $(R)$ between the instruments (Table 3). As PTRMS2 used a different inlet than the other three instruments did, its measurements were compared only with PTR-MS1.

Additionally, the overall consistency of the concentration measurements of the four different instruments was investigated by calculating: (1) the mean of all correlation coefficients, (2) the root mean square (RMS) difference of the scatterplot slopes from 1:1 line, and (3) the RMS of the intercepts for each compound (Table 4). The RMS difference between the slopes and 1:1 line $\left(\mathrm{RMS}_{\text {slope }}\right)$ was calculated as

$\mathrm{RMS}_{\text {slope }}=\sqrt{\frac{1}{N} \sum_{i=1}^{N}\left(1-\text { slope }_{i}\right)^{2}}$,

where slope ${ }_{i}$ is the slope of a scatter plot and $N$ is the number of slopes used for the calculation. In an ideal case, the scatter plot slopes are close to unity, and the $\mathrm{RMS}_{\text {slope }}$ is close to zero. The slope and intercept values of a scatter plot depend on the positioning of the two data sets on the $x$ and $y$ axes, thus the all slopes and intercepts were calculated for both axis configurations.

Generally, the measurements of PTR-MS2 were most scattered for all the compounds (Fig. 4). This was at least partly due to the discontinuous measurement cycle of the instrument, which meant that fewer data points ( 8 per hour) were available for calculating the hourly average than were available when using the PTR-MS1 (43 per hour). When fewer data points are used, individual divergent values have larger effects on the average value, as the SD is inversely proportional to the square root of data points. Data from the GC- 

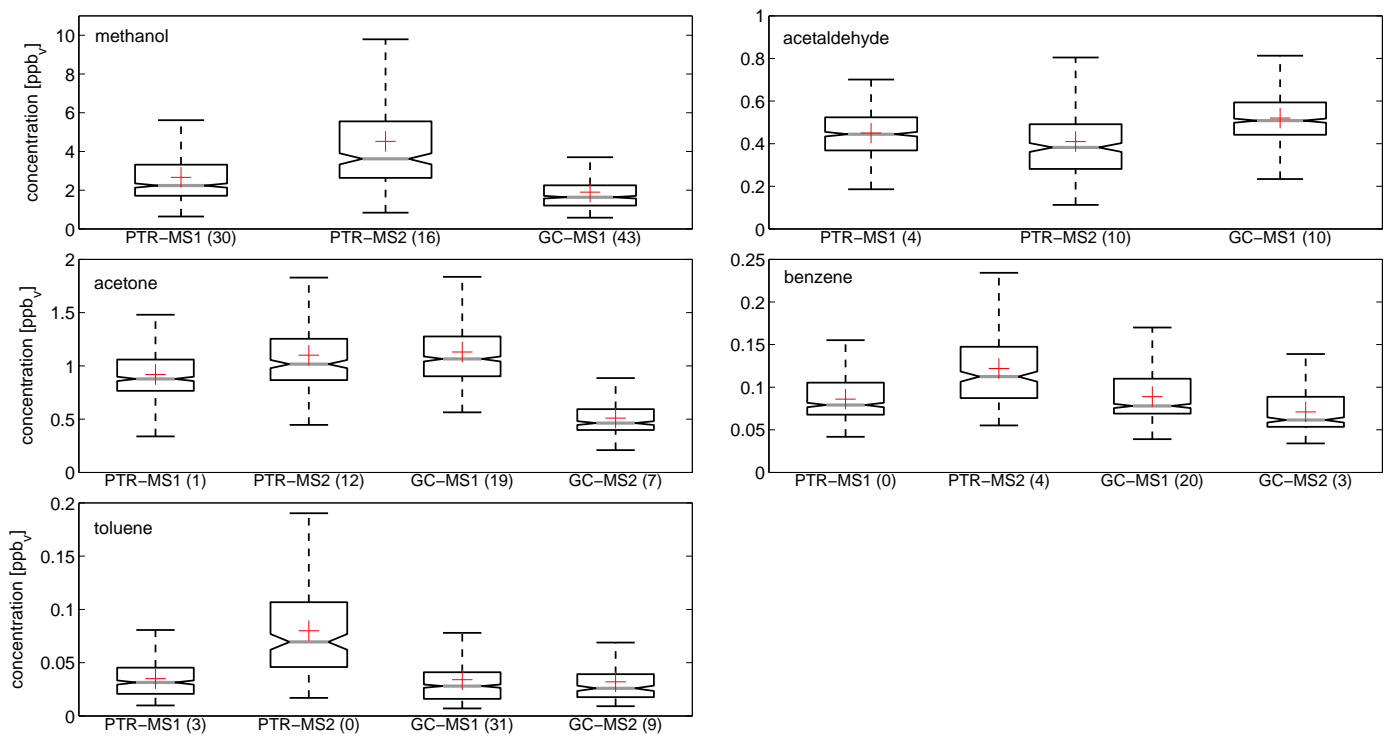

Figure 4. Median concentrations and 25th and 75th percentiles of methanol, acetone, acetaldehyde, benzene and toluene. Red plus signs show the arithmetic mean concentrations. The whiskers illustrate the most extreme data points, which are not considered outliers (99.3\%) and the notches show the $95 \%$ confidence interval of the median value. In order to make the figure more clear, outliers are not shown. The numbers next to the instrument names indicate how many outlier points were removed in each case.

MS2, which had the longest sampling time, were least scattered.

In the following sections, the concentration distributions and correlations between different instruments are discussed separately for all five compounds.

\subsubsection{Methanol}

Methanol was measured with three out of four instruments: PTR-MS1, PTR-MS2 and GC-MS1. There were large differences in the concentration ranges of the methanol measurements (Fig. 4). PTR-MS2 measured the highest concentrations, varying from 2.6 to $5.5 \mathrm{ppb}$. The measurements of PTR-MS1 and GC-MS1 were less scattered and the ranges were more congruent: $1.7-3.3$ and $1.2-2.6 \mathrm{ppb}$ respectively. Also, the median methanol concentration of PTRMS2 (3.6 ppb) was clearly higher than the median of PTRMS1 (2.4 ppb), whereas the median concentration measured with GC-MS1 was the lowest (1.6 ppb). It is important to note that the measurement uncertainty of PTR-MS1 was very high for methanol (Table 1).

As Fig. 5 and Table 1 show, the correlation between the two PTR-MS instruments was very good $(R=0.96)$, but the linear regression slope was 1.80 . Thus, concentrations measured with PTR-MS2 are almost twice as high as those measured with PTR-MS1. The correlation between PTR-MS1 and GC-MS1 was also good (0.84), but between these two instruments there was a constant offset and the slope was far from one (0.42). The mean correlations and RMS values of the slopes and intercepts are presented in Table 3, which shows that the measured methanol concentrations correlated well but the RMS $S_{\text {slope }}$ of 0.87 was far from the ideal $1: 1$ slope.

For methanol the correlation coefficients of this study agreed with those found in prior research. de Gouw et al. (2003b, 2004) and Kaser et al. (2013) reported $R$ values above 0.92 and slope values between 1.03 and 1.16 for PTR-MS vs. GC-MS, PTR-MS vs. PTR-MS and PTR-MS vs. PTR-Tof-MS, respectively. In this study the slopes were clearly less robust than in previous studies, indicating that the time trends of methanol can be captured well with all instruments, but also suggesting that the quantitative concentration values of all three instruments should be regarded with suspicion.

Methanol measurements are known to encounter some challenges. Calibrating PTR-MS for methanol is difficult because methanol deposits on the metal surfaces of the calibration system (de Gouw et al., 2003a), reducing the apparent sensitivity and potentially making the concentrations seem higher than they actually are. However, in our study the systems used to calibrate the two PTR-MS instruments were identical, thus having the same materials. Furthermore, an oxygen isotope $\left(\mathrm{O}^{17} \mathrm{O}\right)$ is detected with the same mass (33 amu) as methanol in the PTR-MS. However, this is not a problem as it is taken into account in the VMR calculation (Taipale et al., 2008). Apart from the oxygen isotope, no significant interference of any other species has been reported in the literature (de Gouw and Warneke, 2007).

The solubility of methanol in water can introduce problems to the GC-MS measurements, because when water is removed from the sample, part of the methanol could be re- 

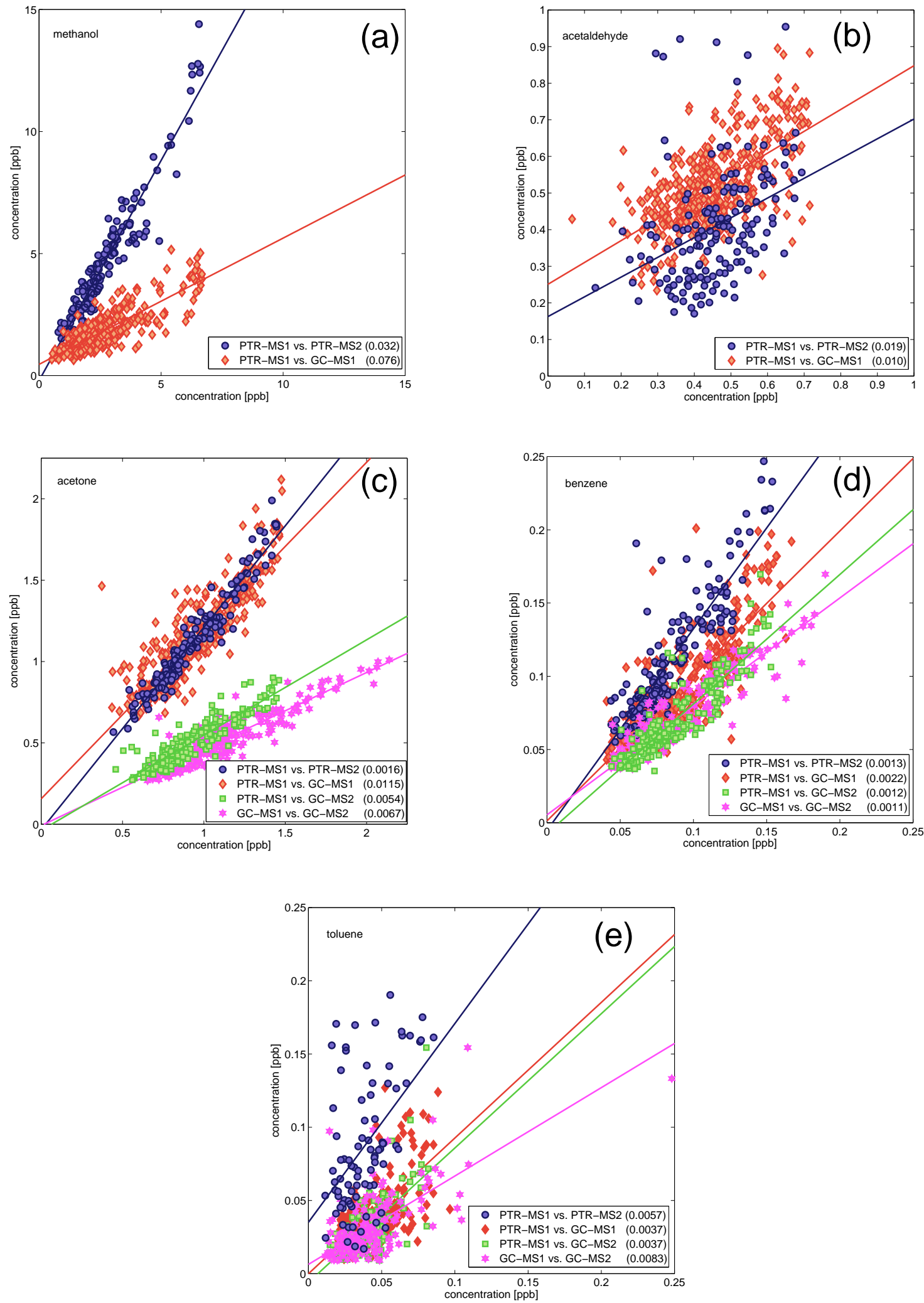

Figure 5. Comparison of volume mixing ratios of methanol, acetaldehyde, acetone, benzene and toluene measured by four different instruments. PTR-MS1 was compared against all three other instruments and the two GC-MSs were compared to each other. Solid lines represent linear fits and the number in brackets goodness of the fits normalized to the number of data points. 
Table 3. Statistical parameters of the correlation analysis for the measured compounds. $N$ is the number of data points considered in the correlation analysis and $R$ the correlation between two instruments for each compound. Parameters $a$ and $b$ are the slope and the offset of a linear fit, respectively.

\begin{tabular}{lrrrr}
\hline & $a$ & $b$ [ppb] & $R$ & $N$ \\
\hline methanol & & & & \\
\hline PTR-MS1 vs. PTR-MS2 & $1.80 \pm 0.08$ & $-0.20 \pm 0.25$ & 0.96 & 159 \\
PTR-MS1 vs. GC-MS1 & $0.52 \pm 0.03$ & $0.46 \pm 0.10$ & 0.84 & 392 \\
PTR-MS1 vs. GC-MS2 & - & - & - & - \\
GC-MS1 vs. GC-MS2 & - & - & - & - \\
\hline acetaldehyde & & & & \\
\hline PTR-MS1 vs. PTR-MS2 & $0.54 \pm 0.21$ & $0.16 \pm 0.10$ & 0.37 & 160 \\
PTR-MS1 vs. GC-MS1 & $0.60 \pm 0.07$ & $0.25 \pm 0.03$ & 0.62 & 425 \\
PTR-MS1 vs. GC-MS2 & - & - & - & - \\
GC-MS1 vs. GC-MS2 & - & - & - & - \\
\hline acetone & & & & \\
\hline PTR-MS1 vs. PTR-MS2 & $1.25 \pm 0.05$ & $-0.04 \pm 0.05$ & 0.97 & 162 \\
PTR-MS1 vs. GC-MS1 & $1.03 \pm 0.05$ & $0.16 \pm 0.05$ & 0.88 & 423 \\
PTR-MS1 vs. GC-MS2 & $0.59 \pm 0.04$ & $-0.04 \pm 0.04$ & 0.91 & 206 \\
GC-MS1 vs. GC-MS2 & $0.47 \pm 0.03$ & $-0.01 \pm 0.01$ & 0.77 & 237 \\
\hline benzene & & & & \\
\hline PTR-MS1 vs. PTR-MS2 & $1.38 \pm 0.11$ & $-0.01 \pm 0.01$ & 0.88 & 168 \\
PTR-MS1 vs. GC-MS1 & $0.99 \pm 0.06$ & $0.001 \pm 0.005$ & 0.84 & 449 \\
PTR-MS1 vs. GC-MS2 & $0.88 \pm 0.06$ & $-0.01 \pm 0.01$ & 0.89 & 213 \\
GC-MS1 vs. GC-MS2 & $0.74 \pm 0.04$ & $0.005 \pm 0.003$ & 0.92 & 280 \\
\hline toluene & & & & \\
\hline PTR-MS1 vs. PTR-MS2 & $1.36 \pm 0.52$ & $0.04 \pm 0.02$ & 0.50 & 85 \\
PTR-MS1 vs. GC-MS1 & $0.55 \pm 0.11$ & $-0.01 \pm 0.01$ & 0.53 & 232 \\
PTR-MS1 vs. GC-MS2 & $0.92 \pm 0.18$ & $-0.01 \pm 0.01$ & 0.69 & 118 \\
GC-MS1 vs. GC-MS2 & $0.60 \pm 0.07$ & $0.006 \pm 0.004$ & 0.77 & 182 \\
\hline
\end{tabular}

moved as well. To correct for the methanol loss in water trap we used information from two previous intercomparison campaigns. A laboratory intercomparison campaign was conducted in 2005 in Germany, during which OVOCs were measured with several GC-MS instruments at the SAPHIR chamber at Forschungszentrum Jülich (see Apel et al., 2008, for details). During the campaign, the SAPHIR chamber was filled with ambient air and spiked with an unknown number of compounds. The results of the GC-MS1 showed overall good agreement with the other instruments, though a tendency to underestimate the mole fractions in the chamber was observed. For methanol, the loss was around $40 \%$ and it was suspected to occur in the bulk trap during the water removal step. Since the intercomparison in the SAPHIR chamber, the material in the bulk trap of GC-MS1 has aged, and the loss of methanol has increased. During an ACTRIS OVOC intercomparison at Hohenpeissenberg (Germany) in October 2013, the methanol loss was 55\% (unpublished). The methanol concentrations measured during this campaign were corrected for the $55 \%$ loss.

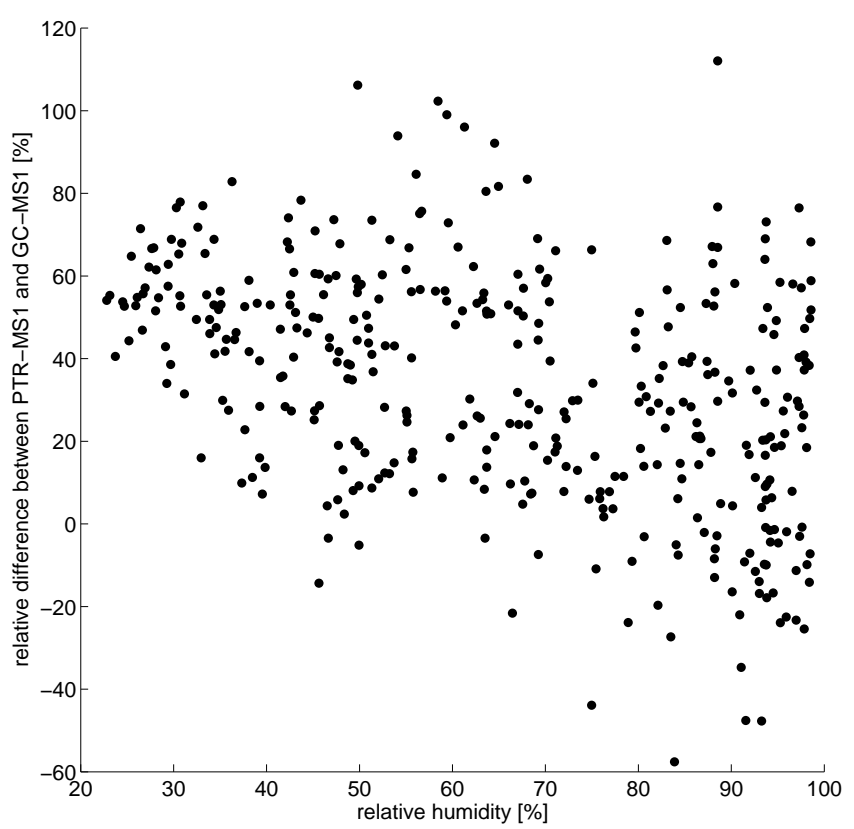

Figure 6. Relative difference of the methanol measurements with PTR-MS1 and GC-MS1 against RH.

Possible causes for the discrepancies between the two instrument pairs were investigated by comparing the differences in the measured VOC concentrations against meteorological parameters temperature, relative humidity $(\mathrm{RH})$, and wind direction and speed. In case of the two PTR-MS instruments none of these meteorological parameters explained the discrepancy between the instruments. The difference between methanol concentrations measured by PTR-MS1 and GC-MS1 seems to depend slightly on RH, (Fig. 6), while other meteorological parameters had no effect. The reason for the RH dependency is unknown. However, the methanol loss of the GC-MS1 due to water removal could be dependent on RH.

\subsubsection{Acetaldehyde}

Three instruments out of four, PTR-MS1, PTR-MS2 and GC-MS1, measured acetaldehyde. The concentration range was very similar for all the instruments, between 0.3 and $0.6 \mathrm{ppb}$ (Fig. 4). Also, the median concentrations of 0.4, 0.4 and $0.5 \mathrm{ppb}$ for PTR-MS1, PTR-MS2 and GC-MS1 respectively, are within a $25 \%$ range of each other. Despite the similar concentration distributions, the correlation between PTR-MS1 and PTR-MS2 was only 0.37 . The correlation between PTR-MS1 and GC-MS1 was better (0.62). Moreover, the slopes for both instrument pairs were quite far from unity: 0.54 for PTR-MS1 vs. PTR-MS2 and 0.60 for PTR-MS1 vs. GC-MS1. The poor slope values resulted in a high $\mathrm{RMS}_{\text {slope }}$ value of 0.50 . For both instrument pairs, the intercepts differed considerably from zero, which was probably caused by difference in the instrumental backgrounds. 


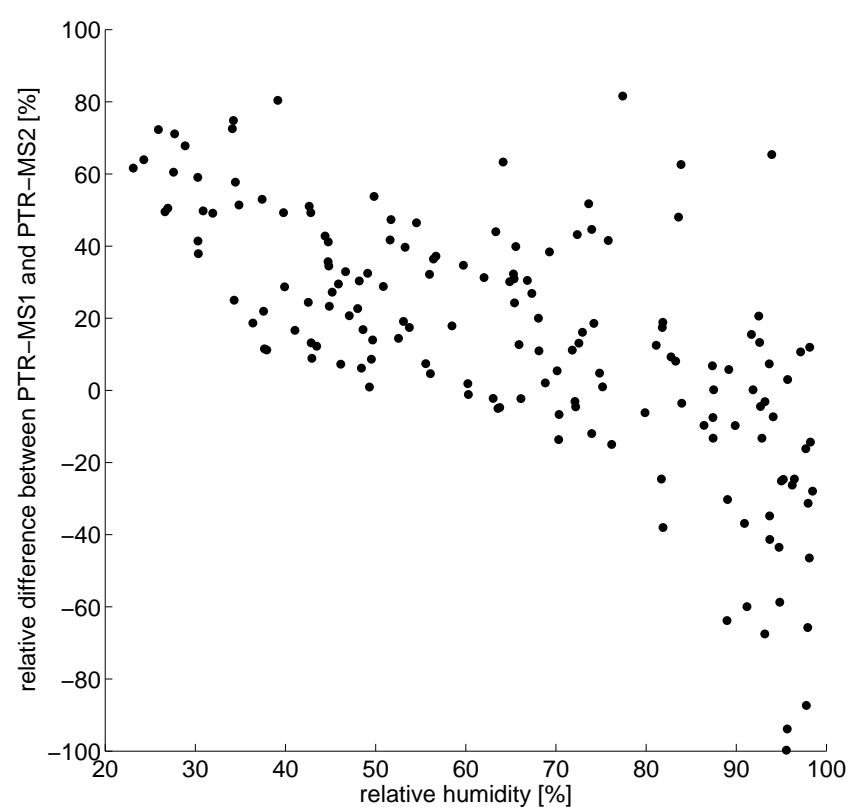

Figure 7. Relative difference of the acetaldehyde measurements with PTR-MS1 and PTR-MS2 against RH.

The correlations of this study were weaker than the correlation reported by de Gouw et al. (2003b) (PTR-MS vs. GC-MS) and Kaser et al. (2013) (PTR-MS vs. PTR-Tof-MS). The slopes of both this study and the study by de Gouw et al. (2003b) are equally far from one, while Kaser et al. (2013) reported a slope close to one. However, in the study by Kaser et al. (2013) the concentration range was much higher than in our study, up to $3.5 \mathrm{ppb}$.

Temperature and wind properties did not explain any of the concentration divergences between different instruments. Instead, concentration difference of both instrument pairs was observed to depend on RH. This phenomenon was clearly stronger between PTR-MS1 and PTR-MS2 than between PTR-MS1 and GC-MS1 (Fig. 7). RH has a diurnal cycle but if there were diurnal cycle in the concentration differences this would be seen also as temperature dependence of the concentration difference. However, no such dependence was observed. The reason for the humidity dependence of the acetaldehyde concentration difference as measured by the two PTR-MS instruments remain unknown for now.

PTR-MS measures acetaldehyde with a mass of $45 \mathrm{amu}$, but in air masses that are strongly influenced by biogenic emissions, several other compounds with the same mass (isomers) exist (de Gouw et al., 2003a). However, in this study the wind direction did not have an effect on the correlations between the different instrument pairs. Furthermore, de Gouw et al. (2003a) have reported that the acetaldehyde concentration in the calibration gas may decrease over time, which again would lead to an overestimated concentration. The calibration gas standard used in this study was less than 1 -year old during the measurement campaign, thus the ac-
Table 4. Root mean square (RMS) differences of the scatter plot slopes from 1:1 line $\left(\mathrm{RMS}_{\text {slope }}\right)$, RMS of the intercepts $\left(\mathrm{RMS}_{\text {intercept }}\right)$ and mean correlation coefficient values $\bar{R}$ for the measured compounds.

\begin{tabular}{lrrr}
\hline & $\mathrm{RMS}_{\text {slope }}$ & $\mathrm{RMS}_{\text {intercept }}[\mathrm{ppb}]$ & $\bar{R}$ \\
\hline methanol & 0.70 & 0.30 & 0.90 \\
acetaldehyde & 0.50 & 0.15 & 0.50 \\
acetone & 0.54 & 0.01 & 0.88 \\
benzene & 0.23 & 0.001 & 0.88 \\
toluene & 0.45 & 0.006 & 0.62 \\
\hline
\end{tabular}

etaldehyde concentration in the calibration gas was probably not considerably decreased.

\subsubsection{Acetone}

Acetone concentrations were measured with all four instruments. GC-MS1 and PTR-MS2 measured similar acetone concentrations, ranging from 0.9 to $1.3 \mathrm{ppb}$, whereas the range of PTR-MS1 was slightly lower, between 0.8 and $1.1 \mathrm{ppb}$. The lowest concentrations were measured with GCMS2, 0.4-0.6 ppb. The median concentrations of PTR-MS1 (0.9 ppb), PTR-MS2 (1.0 ppb) and GC-MS1 (1.1 ppb) were within $20 \%$, while the median for GC-MS2 was clearly lower $(0.5 \mathrm{ppb})$.

As in previous comparison studies (de Gouw et al., 2003b, 2004; Kaser et al., 2013; Warneke et al., 2015), acetone measurements correlated well in this study. The best correlation coefficient was between the two PTR-MS instruments (0.97). PTR-MS1 also correlated well with both GC-MS1 (0.88) and GC-MS2 (0.91). The different sampling times of the two GC-MS instruments could cause at least part of their lower correlation (0.77), as acetone concentration can vary within $1 \mathrm{~h}$. Furthermore, the slope for PTR-MS1 against GC-MS1 was very good (1.03). However, the intercept was $0.2 \mathrm{ppb}$, indicating a difference in the background levels of acetone for these two instruments. The slope between PTR-MS1 and PTR-MS2 was rather good (1.25). The slopes between GCMS2 and both PTR-MS1 and GC-MS1 were far from unity, 0.56 and 0.47 , respectively. This was probably due to the long sampling time, causing acetone to break through the micro trap. Consequently, even though GC-MS2 measured the time trends of acetone equally well as the other instruments, it underestimated the quantitative concentrations. The average correlation coefficient for acetone was good (0.88), but the low slope values of GC-MS2 plotted against both PTR-MS1 and GC-MS1 were far from unity (Fig. 5), also increased the $\mathrm{RMS}_{\text {slope }}(0.54)$. When the $\mathrm{RMS}_{\text {slope }}$ was calculated only for PTR-MS1 vs. PTR-MS2 and for PTR-MS1 vs. GC-MS1 pairs, it is very close to zero (0.02). Meteorological parameters could not explain the small differences between different instruments. 
PTR-MS measurements of acetone can be affected by propanal, which is detected at the same mass (59 amu) as acetone. GC-MS1 measured propanal concentrations, and during the whole campaign its concentration was less than $5 \%$ of the acetone concentration. Hence in this campaign, it could be assumed that PTR-MS measurements at mass 59 amu were acetone.

\subsubsection{Benzene}

The measured benzene concentrations of all four instruments were in good agreement, as found in previous studies by de Gouw et al. (2003b); Kaser et al. (2013) and Warneke et al. (2015) as well. The concentration ranges of PTR-MS1, GCMS1 and GC-MS2 were similar (0.07-0.11 and 0.07-0.11 and $0.05-0.09 \mathrm{ppb}$ respectively) while the PTR-MS2 measurements fluctuated more, between 0.07 and $0.21 \mathrm{ppb}$. The median concentrations of PTR-MS1 and GC-MS1 were the same $(0.08 \mathrm{ppb})$, while the median of GC-MS2 was $0.06 \mathrm{ppb}$ and the median of PTR-MS2 was $0.11 \mathrm{ppb}$.

In general, the correlations between different instrument pairs were good. The two GC-MS instruments had the highest correlation (0.92), yet the slope was not close to unity (0.77). The low slope value could be due to different sampling times of these instruments. However, as benzene does not have local sources at SMEAR II, changes in benzene concentration are slow and different sampling times should not have a great effect on the measured concentrations. PTRMS1 correlated equally well with both PTR-MS2 and GCMS2 (0.88 and 0.89 respectively). The slope of PTR-MS1 vs. GC-MS2 was reasonably good (0.84), while the slope between the two PTR-MS instruments was rather high (1.38). Between PTR-MS1 and GC-MS1, the correlation was 0.84 and the slope was very good (0.99). The average correlation coefficient of benzene was the same as the mean $R(\bar{R})$ of acetone (0.88), and the $\mathrm{RMS}_{\text {slope }}(0.23)$ was lower than it was for the other compounds. As in the case of acetone, no dependency between meteorological parameters and instrument discrepancies was found.

Good correlations were expected for benzene, as the temporal and spatial changes in benzene concentration are low at the site and there are no known problems concerning benzene measurements with either GC-MS or PTR-MS. PTRMS measurements at mass 79 amu have been reported to be only benzene, thus benzene measurements of PTR-MS are not interfered with other VOCs.

\subsubsection{Toluene}

Toluene was measured with all four instruments. The concentration ranges of PTR-MS1, GC-MS1 and GC-MS2 were the same from 0.02 to $0.05 \mathrm{ppb}$, with a median of $0.03 \mathrm{ppb}$. Due to high detection limits for toluene, the toluene concentrations measured with PTR-MS2 were high (0.05-0.11 ppb) and the median value $(0.07 \mathrm{ppb})$ was more than twice as high as when measured by the other instruments.

Although the concentrations of the three instruments agreed well, their correlation values were only moderate. $\bar{R}$ was 0.62 , while the $\mathrm{RMS}_{\text {slope }}$ was rather far from zero, at 0.45 . The best correlation was between the two GC-MS instruments (0.77). Similarly to benzene, toluene does not have significant local sources at the site. Even though some studies (e.g. Heiden et al., 1999) have shown that under stress, many plant species may emit toluene, a recent study by Rantala et al. (2015) reported only low toluene fluxes during April and May at the site. Thus the effect of the different sampling times of the two GC-MS instruments should not be considerable. Yet, the slope of the GC-MS1 vs. GC-MS2 was far from unity (0.60). Between PTR-MS1 and GC-MS2 the slope was good (0.92), and also the correlation coefficient of 0.69 was fairly good, but the slope had a rather high confidence interval $( \pm 0.18)$. The correlation between PTR-MS1 and GCMS1 was low, 0.53 and slope far from unity (0.55). The lowest correlation was between the two PTR-MS instruments (0.50). Their slope was 1.36 , with a high confidence interval of \pm 0.52 . The toluene concentration remained below the detection limits of the PTR-MS instruments for a large amount of the time during the campaign, biasing the concentrations towards higher values. The number of data points used for the correlation analysis of toluene was less than half of the number of data points used for the other compounds.

In the study by de Gouw et al. (2003b), the correlation between PTR-MS and GC-MS was stronger $(R>0.98$ and slope $=1.08)$ than the correlations found in this study. Additionally, the correlation coefficients between PTR-MS and PTR-Tof-MS reported by Kaser et al. (2013) and Warneke et al. (2015) were stronger than the ones measured during this campaign $(R>0.85)$. However, toluene concentrations were higher during the studies by de Gouw et al. (2003b) and Kaser et al. (2013), 0.003-1 ppb and 0.01-0.25, respectively, than the measurements presented in this study.

Although, large measurement discrepancies were found between different instruments, the explanation for this was unknown. For example, meteorological parameters had no correlation with the concentration differences of different instruments. It has been suggested that a p-cymene fragment is detected at the same mass (93 amu) as toluene with PTR-MS (Ambrose et al., 2010). Kaser et al. (2013) reported that in correcting the toluene signals for $\mathrm{p}$-cymene, the linear regression between PTR-Tof-MS and another mass spectrometer improved from 0.72 to 0.98 . During this campaign, p-cymene parent ion concentrations were not measured with PTR-MS instruments. Earlier measurements at SMEAR II showed that between 12 April and 15 May 2011, the toluene concentration was on average 15 times higher than the p-cymene concentration. The mean p-cymene concentration was $8 \mathrm{ppt}$, while the maximum concentration was 107 ppt (Hakola et al., 2012). Consequently, p-cymene may occasionally have an effect on the toluene concentrations measured with PTR-MS. 
High p-cymene concentrations could be expected, for example, during the monoterpene pollution episodes (Liao et al., 2011) from the nearby saw mill.

\section{Conclusions}

Ambient concentrations of methanol, acetaldehyde, acetone, benzene and toluene were measured using two PTR-MS instruments and two GC-MS instruments at a rural boreal forest site in the spring of 2012. Additionally, two different calibration methods, automatic and manual, were tested for the PTR-MS instruments. The calibration tests showed that both calibration methods resulted in similar sensitivities for acetaldehyde, acetone, benzene and toluene. For methanol, sensitivities obtained with the automatic method resulted in lower apparent sensitivities than the manual calibration method did. Also the sensitivity uncertainties of both PTRMS instruments were higher for methanol than for the other compounds.

Very good correlation was found for benzene and acetone measurements between all instrument pairs. The mean correlation coefficient was 0.88 for both compounds. In the case of acetone, the RMS difference from the $1: 1$ line was high. However, probably due to the long sampling time of the GCMS2, acetone broke through the adsorbent trap, resulting in measured concentrations that were too low. When the acetone data of GC-MS2 was omitted from the calculation, the RMS difference from the $1: 1$ line was close to zero. To measure acetone or other very volatile OVOCs using GC-MS2 it is recommended to use: a shorter sampling time, a lower flow or a stronger or a cooled adsorbent trap.

The correlation coefficients of acetaldehyde and toluene were quite far from unity, with respective averages of 0.50 and 0.62 . The cause of the bad correlation in the case of acetaldehyde remains unresolved. Toluene concentrations were below the detection limits of the PTR-MS instruments for a considerable amount of the time, which biased the concentrations towards higher values and also reduced the amount of data points used for analysis.

Methanol measurements showed a robust correlation between the instruments. However, the slope values were far from unity, with an RMS difference of 0.87 from the $1: 1$ line. Hence, all the instruments measured the same time trends of methanol, but the quantitative concentration values must be regarded with caution. It should be noted that the uncertainty in the sensitivity of the instruments, manifesting as the deviation of the correlation slopes from unity, leads directly to similar uncertainty in the emission measurements of these compounds. This applies to, for example, eddy covariance, surface layer gradient and chamber techniques. Thus, it can be easily estimated that, for example, any emission measurement of methanol has an uncertainty of 50-100\% due to the sensitivity of the instrument used.
This study raises a few open questions yet to be answered. These include the following:

- the reasons for major biases between instruments for many compounds. This may be due to the materials used in different set-ups, but the reason remains unknown for now.

- the reason for RH dependence of the differences in acetaldehyde measurements.

- the constancy of the methanol loss correction in the GCMS1. It is assumed to be constant, which may not be the case.

Technical recommendations arising from this experiment include the following:

- GC-MS sampling time must be adjusted to prevent breakthrough of any compound of interest. Suitable sampling time must be determined individually for each compound and the shortest time used for the measurement protocol.

- for the PTR-MS, the time used for the calibration must be long enough to reach the stable regime. The length of the calibration period must be determined individually for all compounds in the calibration gas, and the actual calibration time is determined as the longest.

The results of this study show that when doing long-term measurements of ambient air, occasional comparison measurements are needed to evaluate the measured concentrations and to quantify the uncertainties, even if the instrument is calibrated regularly. 


\section{Appendix A}

Table A1. Results of the PTR-MS calibration tests. "Manual calibration method" (MCM) refers to the system in which the calibration gas standard and zero air flows are controlled manually with a pressure regulator and needle valves (see Taipale et al., 2008, for details). "Automatic method" (ACM) refers to the calibration mixing units, in which the flows are controlled automatically with mass flow controllers. All parameters of the table are presented in the $\left[\mathrm{ppbncps}^{-1}\right]$ unit. $\bar{S}$ and $\sigma_{S}$ are the mean sensitivity and the standard deviation of the sensitivity, respectively.

\begin{tabular}{|c|c|c|c|c|c|c|c|c|}
\hline & \multicolumn{4}{|c|}{ PTR-MS1 } & \multicolumn{4}{|c|}{ PTR-MS2 } \\
\hline & \multicolumn{2}{|c|}{ MCM } & \multicolumn{2}{|c|}{$\mathrm{ACM}$} & \multicolumn{2}{|c|}{ MCM } & \multicolumn{2}{|c|}{$\mathrm{ACM}$} \\
\hline & $\bar{S}$ & $\sigma_{S}$ & $\bar{S}$ & $\sigma_{S}$ & $\bar{S}$ & $\sigma_{S}$ & $\bar{S}$ & $\sigma_{S}$ \\
\hline methanol & 10.4 & 1.9 & 4.8 & 3.0 & 8.1 & 1.2 & 6.3 & 1.6 \\
\hline acetonitrile & 19.8 & 3.1 & 19.3 & 3.4 & 19.6 & 1.2 & 18.5 & 0.9 \\
\hline acetaldehyde & 15.8 & 2.5 & 15.6 & 1.6 & 15.1 & 0.9 & 12.9 & 0.6 \\
\hline acetone & 16.3 & 2.5 & 17.1 & 2.1 & 19.0 & 1.0 & 18.2 & 0.7 \\
\hline isoprene & 7.9 & 1.2 & 8.7 & 0.5 & 6.0 & 0.3 & 5.9 & 0.7 \\
\hline $\mathrm{MVK}^{1}$ & 14.6 & 2.3 & 10.3 & 1.6 & 15.1 & 0.9 & 9.1 & 0.3 \\
\hline $\mathrm{MEK}^{2}$ & 14.0 & 2.2 & 14.9 & 2.2 & 17.1 & 1.0 & 16.4 & 0.6 \\
\hline benzene & 7.4 & 1.1 & 8.3 & 0.5 & 9.4 & 0.5 & 9.3 & 0.3 \\
\hline toluene & 7.1 & 1.0 & 8.1 & 0.7 & 10.6 & 0.6 & 10.4 & 0.2 \\
\hline xylenes & 5.2 & 0.8 & 5.7 & 0.8 & 10.9 & 0.6 & 10.9 & 0.3 \\
\hline trimethylbenzene & 3.6 & 0.5 & 3.7 & 0.7 & 10.5 & 0.6 & 10.9 & 0.5 \\
\hline naphthalene & 5.7 & 0.7 & 3.6 & 1.7 & 15.6 & 1.1 & 15.6 & 3.4 \\
\hline$\alpha$-pinene & 1.1 & 0.2 & 1.2 & 0.2 & 3.8 & 0.2 & 3.9 & 0.1 \\
\hline
\end{tabular}

${ }^{1}$ MVK: methyl vinyl ketone; ${ }^{2}$ MEK: metyl etyl ketone. 


\section{The Supplement related to this article is available online at doi:10.5194/amt-8-4453-2015-supplement.}

Acknowledgements. This work was financially supported by ACTRIS Research Infrastructure Project, which is supported by the European Union Seventh Framework Programme (FP7/2007-2013) under grant agreement no. 262254, from the ACTRIS TNA "OVOC analysis for Total Observed Organic Carbon determination (OVOC-TOOC)" and from the Academy of Finland Center of Excellence program (projects 1118615 and 272041). We thank Rae Ellen Bichell for proofreading the manuscript.

Edited by: N. Yassaa

\section{References}

Aalto, J., Kolari, P., Hari, P., Kerminen, V.-M., Schiestl-Aalto, P., Aaltonen, H., Levula, J., Siivola, E., Kulmala, M., and Bäck, J.: New foliage growth is a significant, unaccounted source for volatiles in boreal evergreen forests, Biogeosciences, 11, 13311344, doi:10.5194/bg-11-1331-2014, 2014.

Aaltonen, H., Aalto, J., Kolari, P., Pihlatie, M., Pumpanen, J., Kulmala, M., Nikinmaa, E., Vesala, T., and Bäck, J.: Continuous VOC flux measurements on boreal forest floor, Plant Soil, 369, 241-256, 2013.

Ambrose, J. L., Haase, K., Russo, R. S., Zhou, Y., White, M. L., Frinak, E. K., Jordan, C., Mayne, H. R., Talbot, R., and Sive, B. C.: A comparison of GC-FID and PTR-MS toluene measurements in ambient air under conditions of enhanced monoterpene loading, Atmos. Meas. Tech., 3, 959-980, doi:10.5194/amt3-959-2010, 2010.

Apel, E. C., Calvert, J. G., and Fehsenfeld, F. C.: The Nonmethane Hydrocarbon Intercomparison Experiment (NOMHICE): tasks 1 and 2, J. Geophys. Res., 99, 16651-16664, doi:10.1029/94JD00086, 1994.

Apel, E., Calvert, J., Gilpin, T., Fehsenfeld, F., Parrish, D., and Lonneman, W. A.: The Nonmethane Hydrocarbon Intercomparison Experiment (NOMHICE): task 3, J. Geophys. Res., 104, 26069 26086, doi:10.1029/1999JD900793, 1999.

Apel, E., Calvert, J., Gilpin, T., Fehsenfeld, F., and Lonneman, W. A.: Nonmethane Hydrocarbon Intercomparison Experiment (NOMHICE): task 4, ambient air, J. Geophys. Res., 108, 4300, doi:10.1029/2002JD002936, 2003.

Apel, E. C., Brauers, T., Koppmann, R., Bandowe, B., Bossmeyer, J., Holzke, C., Tillmann, R., Wahner, A., Wegener, R., Brunner, A., Jocher, M., Ruuskanen, T., Spirig, C., Steigner, D., Steinbrecher, R., Gomez Alvarez, E., Müller, K., Burrows, J. P., Schade, G., Solomon, S. J., Ladstätter-Weissenmayer, A., Simmonds, P., Young, D., Hopkins, J. R., Lewis, A. C., Legreid, G., Reimann, S., Hansel, A., Wisthaler, A., Blake, R. S., Ellis, A. M., Monks, P. S., and Wyche, K. P.: Intercomparison of oxygenated volatile organic compound measurements at the SAPHIR atmosphere simulation chamber, J. Geophys. Res.-Atmos., 113, D20307, doi:10.1029/2008JD009865, 2008.
Apel, E. C., Emmons, L. K., Karl, T., Flocke, F., Hills, A. J., Madronich, S., Lee-Taylor, J., Fried, A., Weibring, P., Walega, J., Richter, D., Tie, X., Mauldin, L., Campos, T., Weinheimer, A., Knapp, D., Sive, B., Kleinman, L., Springston, S., Zaveri, R., Ortega, J., Voss, P., Blake, D., Baker, A., Warneke, C., WelshBon, D., de Gouw, J., Zheng, J., Zhang, R., Rudolph, J., Junkermann, W., and Riemer, D. D.: Chemical evolution of volatile organic compounds in the outflow of the Mexico City Metropolitan area, Atmos. Chem. Phys., 10, 2353-2375, doi:10.5194/acp-102353-2010, 2010.

Atkinson, R. and Arey, J.: Atmospheric chemistry of biogenic organic compounds, Accounts Chem. Res., 31, 574-583, 1998.

Atkinson, R. and Arey, J.: Gas-phase tropospheric chemistry of biogenic volatile organic compounds: a review, Atmos. Environ., 37, 197-219, doi:10.1016/S1352-2310(03)00391-1, 2003.

Birmili, W., Berresheim, H., Plass-Dülmer, C., Elste, T., Gilge, S., Wiedensohler, A., and Uhrner, U.: The Hohenpeissenberg aerosol formation experiment (HAFEX): a long-term study including size-resolved aerosol, $\mathrm{H}_{2} \mathrm{SO}_{4}, \mathrm{OH}$, and monoterpenes measurements, Atmos. Chem. Phys., 3, 361-376, doi:10.5194/acp-3-361-2003, 2003.

de Gouw, J. and Warneke, C.: Measurements of volatile organic compounds in the earth's atmosphere using proton-transferreaction mass spectrometry, Mass Spectrom. Rev., 26, 223-257, 2007.

de Gouw, J., Warneke, C., Karl, T., Eerdekens, G., van der Veen, C., and Fall, R.: Sensitivity and specificity of atmospheric trace gas detection by proton-transfer-reaction mass spectrometry, Int. J. Mass Spectrom., 223-224, 365-382, doi:10.1016/S13873806(02)00926-0, 2003a.

de Gouw, J. A., Goldan, P., Warneke, C., Kuster, W. C., Roberts, J. M., Marchewka, M., Bertman, S. B., Pszenny, A. A. P., and Keene, W. C.: Validation of proton transfer reaction-mass spectrometry (PTR-MS) measurements of gas phase organic compounds in the atmosphere during the NEW England Air Quality Study (NEAQS) in 2002, J. Geophys. Res.-Atmos., 108, 4682, doi:10.1029/2003JD003965, 2003 b.

de Gouw, J., Warneke, C., Holzinger, R., Klüpfel, T., and Williams, J.: Inter-comparison between airborne measurements of methanol, acetonitrile and acetone using two differently configured PTR-MS instruments, Int. J. Mass Spectrom., 2, 129137, 2004.

Fast, J. D., Gustafson Jr., W. I., Easter, R. C., Zaveri, R. A., Barnard, J. C., Chapman, E. G., Grell, G. A., and Peckham, S. E.: Evolution of ozone, particulates, and aerosol direct radiative forcing in the vicinity of Houston using a fully coupled meteorology-chemistry-aerosol model, J. Geophys. Res., 111, D21305, doi:10.1029/2005JD006721, 2006.

Filella, I. and Peñuelas, J.: Daily, weekly, and seasonal time courses of VOC concentrations in a semi-urban area near Barcelona, Atmos. Environ., 40, 7752-7769, doi:10.1016/j.atmosenv.2006.08.002, 2006.

Goldstein, A. H. and Galbally, I. E.: Known and unexplored organic constituents in the earth's atmosphere, Environ. Sci. Technol., 41, 1514-1521, doi:10.1021/es072476p, 2007.

Goldstein, A. H. and Schade, G. W.: Quantifying biogenic and anthropogenic contributions to acetone mixing ratios in a rural environment, Atmos. Environ., 34, 4997-5006, doi:10.1016/S13522310(00)00321-6, 2000. 
Grosjean, E., Rasmussen, R. A., and Grosjean, D.: Ambient levels of gas phase pollutants in Porto Alegre, Brazil, Atmos. Environ., 32, 3371-3379, doi:10.1016/S1352-2310(98)00007-7, 1998.

Grote, R. and Niinemets, U.: Modeling volatile isoprenoid emissions - a story with split ends, Plant Biol., 10, 8-28, doi:10.1055/s-2007-964975, 2008.

Guenther, A., Hewitt, C. N., Erickson, D., Fall, R., Geron, C., Harley, T. G. P., Klinger, L., Lerdau, M., McKay, W. A., Pierce, T., Scholes, B., Tallamraju, R. S. R., Taylor, J., and Zimmerman, P.: A global model of natural volatile organic compound emissions, J. Geophys. Res., 100, 8873-8892, 1995.

Guenther, A. B., Jiang, X., Heald, C. L., Sakulyanontvittaya, T., Duhl, T., Emmons, L. K., and Wang, X.: The Model of Emissions of Gases and Aerosols from Nature version 2.1 (MEGAN2.1): an extended and updated framework for modeling biogenic emissions, Geosci. Model Dev., 5, 1471-1492, doi:10.5194/gmd-51471-2012, 2012.

Hakola, H., Tarvainen, V., Laurila, T., Hiltunen, V., Hellén, H., and Keronen, P.: Seasonal variation of VOC concentrations above a boreal coniferous forest, Atmos. Environ., 37, 1623-1634, doi:10.1016/S1352-2310(03)00014-1, 2003.

Hakola, H., Hellén, H., Tarvainen, V., Bäck, J., Patokoski, J., and Rinne, J.: Annual variations of atmospheric VOC concentrations in a boreal forest, Boreal Environ. Res., 14, 722-730, 2009.

Hakola, H., Hellén, H., Hemmilä, M., Rinne, J., and Kulmala, M.: In situ measurements of volatile organic compounds in a boreal forest, Atmos. Chem. Phys., 12, 11665-11678, doi:10.5194/acp12-11665-2012, 2012.

Hari, P. and Kulmala, M.: Station for Measuring EcosystemAtmosphere Relations (SMEAR II), Boreal Environ. Res., 10, 315-322, 2005.

Heiden, A. C., Kobel, K., Komenda, M., Koppmann, R., Shao, M., and Wildt, J.: Toluene emissions from plants, Geophys. Res. Lett., 26, 1283-1286, 1999.

Hellén, H., Hakola, H., and Laurila, T.: Determination of source contributions of NMHCs in Helsinki $\left(60^{\circ} \mathrm{N}, 25^{\circ} \mathrm{E}\right)$ using chemical mass balance and the Unmix multivariate receptor models, Atmos. Environ., 37, 1413-1424, doi:10.1016/S13522310(02)01049-X, 2003.

Hellén, H., Hakola, H., Pirjola, L., Laurila, T., and Pystynen, K.H.: Ambient air concentrations, source profiles and source apportionment of 71 different $\mathrm{C} 2-\mathrm{C} 10$ volatile organic compounds in urban and residential areas of Finland, Environ. Sci. Technol., 40, 103-108, 2006.

Hellén, H., Hakola, H., Haaparanta, S., Pietarila, H., and Kauhaniemi, M.: Influence of residential wood combustion on local air quality, Sci. Total Environ., 393, 283-290, doi:10.1016/j.scitotenv.2008.01.019, 2008.

Hellén, H., Kuronen, P., and Hakola, H.: Heated stainless steel tube for ozone removal in the ambient air measurements of mono- and sesquiterpenes, Atmos. Environ., 57, 35-40, doi:10.1016/j.atmosenv.2012.04.019, 2012a.

Hellén, H., Tykkä, T., and Hakola, H.: Importance of isoprene and monoterpenes in urban air in Northern Europe, Atmos. Environ., 59, 59-66, 2012b.

Helmig, D., Petrenko, V., Martinerie, P., Witrant, E., Röckmann, T., Zuiderweg, A., Holzinger, R., Hueber, J., Thompson, C., White, J. W. C., Sturges, W., Baker, A., Blunier, T., Etheridge, D., Rubino, M., and Tans, P.: Reconstruction of North- ern Hemisphere 1950-2010 atmospheric non-methane hydrocarbons, Atmos. Chem. Phys., 14, 1463-1483, doi:10.5194/acp-141463-2014, 2014.

Hoerger, C. C., Werner, A., Plass-Duelmer, C., Reimann, S., Eckart, E., Steinbrecher, R., Aalto, J., Arduini, J., Bonnaire, N., Cape, J. N., Colomb, A., Connolly, R., Diskova, J., Dumitrean, P., Ehlers, C., Gros, V., Hakola, H., Hill, M., Hopkins, J. R., Jäger, J., Junek, R., Kajos, M. K., Klemp, D., Leuchner, M., Lewis, A. C., Locoge, N., Maione, M., Martin, D., Michl, K., Nemitz, E., O’Doherty, S., Pérez Ballesta, P., Ruuskanen, T. M., Sauvage, S., Schmidbauer, N., Spain, T. G., Straube, E., Vana, M., Vollmer, M. K., Wegener, R., and Wenger, A.: ACTRIS non-methane hydrocarbon intercomparison experiment in Europe to support WMO-GAW and EMEP observation networks, Atmos. Meas. Tech. Discuss., 7, 1042310485, doi:10.5194/amtd-7-10423-2014, 2014.

Holst, T., Arneth, A., Hayward, S., Ekberg, A., Mastepanov, M., Jackowicz-Korczynski, M., Friborg, T., Crill, P. M., and Bäckstrand, K.: BVOC ecosystem flux measurements at a high latitude wetland site, Atmos. Chem. Phys., 10, 1617-1634, doi:10.5194/acp-10-1617-2010, 2010.

Holzinger, R., Millet, D. B., Williams, B., Lee, A., Kreisberg, N., Hering, S., Jimenez, J., Allan, J., Worsnop, D., and Goldstein, A. H.: Emission, oxidation, and secondary organic aerosol formation of volatile organic compounds as observed at Chebogue Point, Nova Scotia, J. Geophys. Res.-Atmos., 112 , 1463-1483, doi:10.1029/2006JD007599, 2007.

Ilvesniemi, H., Pumpanen, J., Duursma, R., Hari, P., Keronen, P., Kolari, P., Kulmala, M., Mammarella, I., Nikinmaa, E., Rannik, U., Pohja, T., Siivola, E., and Vesala, T.: Water balance of a boreal Scots pine forest, Boreal Environ. Res., 15, 375-396, doi:10.1029/2006JD007599, 2010.

Jenkin, M. E., Saunders, S. M., and Pilling, M.: The tropospheric degradation of volatile organic compounds: a protocol for mechanism development, Atmos. Environ., 31, 81-104, 1997.

Jordan, C., Fitz, E., Hagan, T., Sive, B., Frinak, E., Haase, K., Cottrell, L., Buckley, S., and Talbot, R.: Long-term study of VOCs measured with PTR-MS at a rural site in New Hampshire with urban influences, Atmos. Chem. Phys., 9, 4677-4697, doi:10.5194/acp-9-4677-2009, 2009.

Karl, T., Jobson, T., Kuster, W. C., Williams, E., Stutz, J., Shetter, R., Hall, S. R., Goldan, P., Fehsenfeld, F., and Lindinger, W.: Use of proton-transfer-reaction mass spectrometry to characterize volatile organic compound sources at the La Porte super site during the Texas Air Quality Study 2000, J. Geophys. Res., 108, 4508, doi:10.1029/2002JD003333, 2003.

Kaser, L., Karl, T., Schnitzhofer, R., Graus, M., HerdlingerBlatt, I. S., DiGangi, J. P., Sive, B., Turnipseed, A., Hornbrook, R. S., Zheng, W., Flocke, F. M., Guenther, A., Keutsch, F. N., Apel, E., and Hansel, A.: Comparison of different real time VOC measurement techniques in a ponderosa pine forest, Atmos. Chem. Phys., 13, 2893-2906, doi:10.5194/acp-132893-2013, 2013.

Kesselmeier, J., Bode, K., Hofmann, U., Müller, H., Schäfer, L., Wolf, A., Ciccioli, P., Brancaleoni, E., Cecinato, A., Frattoni, M., Foster, P., Ferrari, C., Jacob, V., Fugit, J. L., Dutaur, L., Simon, V., and Torres, L.: Emission of short chained organic acids, aldehydes and monoterpenes from Quercus ilex L., and Pinus 
pinea $\mathrm{L}$. in relation to physiological activities, carbon budget and emission algorithms, Atmos. Environ., 31, 119-133, 1997.

Kolari, P., Bäck, J., Taipale, R., Ruuskanen, T. M., Kajos, M. K., Rinne, J., Kulmala, M., and Hari, P.: Evaluation of accuracy in measurements of VOC emissions with dynamic chamber system, Atmos. Environ., 62, 344-351, 2012.

Kulmala, M., Dal Maso, M., Mäkelä, J., Pirjola, L., Väkevä, M., Aalto, P., Miikkulainen, P., Hämeri, K., and O'Dowd, C.: On the formation, growth and composition of nucleation mode particles, Tellus B, 53, 479-490, doi:10.1034/j.1600-0889.2001.530411.x, 2001

Legreid, G., Lööv, J. B., Staehelin, J., Hueglin, C., Hill, M., Buchmann, B., Prevot, A. S. H., and Reimann, S.: Oxygenated volatile organic compounds (OVOCs) at an urban background site in Zürich (Europe): seasonal variation and source allocation, Atmos. Environ., 41, 8409-8423, 2007.

Legreid, G., Folini, D., Staehelin, J., Lööv, J. B., Steinbacher, M., and Reimann, S.: Measurements of organic trace gases including oxygenated volatile organic compounds at the high alpine site Jungfraujoch (Switzerland): seasonal variation and source allocations, J. Geophys. Res.-Atmos., 113, D05307, doi:10.1029/2007JD008653, 2008.

Lelieveld, J., Butler, T., Crowley, J., Dillon, T., Fischer, H., Ganzeveld, L., Harder, H., Lawrence, M., Martinez, M., Taraborrelli, D., and Williams, J.: Atmospheric oxidation capacity sustained by a tropical forest, Nature, 452, 737-740, doi:10.1038/nature06870, 2008.

Lewis, A., Bartle, K., Heard, D., McQuaid, J., Pilling, M., and Seakins, P.: In situ, gas chromatographic measurements of nonmethane hydrocarbons and dimethyl sulfide at a remote coastal location (Mace Head, Eire) July-August 1996, J. Chem. Soc. Faraday T., 93, 2921-2927, doi:10.1039/a701566f, 1997.

Liao, L., Dal Maso, M., Taipale, R., Rinne, J., Ehn, M., Junninen, H., Äijälä, M., Nieminen, T., Alekseychik, P., Hulkkonen, M., Worsnop, D. R., Kerminen, V.-M., and Kulmala, M.: Monoterpene pollution episodes in a forest environment: indication of anthropogenic origin and association with aerosol particles, Boreal Environ. Res., 16, 288-303, 2011.

Lindinger, W., Hansel, A., and Jordan, A.: On-line monitoring of volatile organic compounds at pptv levels by means of ProtonTransfer-Reaction Mass Spectrometry (PTR-MS) - medical applications, food control and environmental research, Int. J. Mass Spectrom., 173, 191-241, 1998.

Lopez-Hilfiker, F. D., Mohr, C., Ehn, M., Rubach, F., Kleist, E., Wildt, J., Mentel, T. F., Lutz, A., Hallquist, M., Worsnop, D., and Thornton, J. A.: A novel method for online analysis of gas and particle composition: description and evaluation of a Filter Inlet for Gases and AEROsols (FIGAERO), Atmos. Meas. Tech., 7, 983-1001, doi:10.5194/amt-7-983-2014, 2014.

Makkonen, R., Asmi, A., Kerminen, V.-M., Boy, M., Arneth, A., Guenther, A., and Kulmala, M.: BVOC-aerosol-climate interactions in the global aerosol-climate model ECHAM5.5-HAM2, Atmos. Chem. Phys., 12, 10077-10096, doi:10.5194/acp-1210077-2012, 2012.

Maleknia, S. D., Bell, T. L., and Adams, M. A.: PTR-MS analysis of reference and plant-emitted volatile organic compounds, Int. J. Mass Spectrom., 262, 203-210, 2007.

Miller, B. R., Weiss, R., Salameh, P., Tanhua, T., Greally, B. R., Muhle, J., and Simmonds, P.: Medusa: A sample preconcentra- tion and GC/MS detector system for in situ measurements of atmospheric trace halocarbons, hydrocarbons, and sulfur compounds, Anal. Chem., 80, 1536-1545, doi:10.1021/ac702084k, 2008.

Millet, D. B., Guenther, A., Siegel, D. A., Nelson, N. B., Singh, H. B., de Gouw, J. A., Warneke, C., Williams, J., Eerdekens, G., Sinha, V., Karl, T., Flocke, F., Apel, E., Riemer, D. D., Palmer, P. I., and Barkley, M.: Global atmospheric budget of acetaldehyde: 3-D model analysis and constraints from in-situ and satellite observations, Atmos. Chem. Phys., 10, 3405 3425, doi:10.5194/acp-10-3405-2010, 2010.

Misztal, P. K., Heal, M. R., Nemitz, E., and Cape, J. N.: Development of PTR-MS selectivity for structural isomers: Monoterpenes as a case study, Int. J. Mass Spectrom., 310, 10-19, 2012.

Molina, L. T., Madronich, S., Gaffney, J. S., Apel, E., de Foy, B., Fast, J., Ferrare, R., Herndon, S., Jimenez, J. L., Lamb, B., Osornio-Vargas, A. R., Russell, P., Schauer, J. J., Stevens, P. S., Volkamer, R., and Zavala, M.: An overview of the MILAGRO 2006 Campaign: Mexico City emissions and their transport and transformation, Atmos. Chem. Phys., 10, 8697-8760, doi:10.5194/acp-10-8697-2010, 2010.

Munson, B.: Development of chemical ionization mass spectrometry, Int. J. Mass Spectrom., 200, 243-251, doi:10.1016/S13873806(00)00301-8, 2000.

Na, K. and Kim, Y. P.: Seasonal characteristics of ambient volatile organic compounds in Seoul, Korea, Atmos. Environ., 35, 2603 2614, doi:10.1016/S1352-2310(00)00464-7, 2001.

Paasonen, P., Asmi, A., Petäjä, T., Kajos, M. K., Äijälä, M., Junninen, H., Holst, T., Abbatt, J. P. D., Arneth, A., Birmili, W., van der Gon, H. A. C. D., Hamed, A., Hoffer, A., Laakso, L., Laaksonen, A., Leaitch, W. R., Plass-Dülmer, C., Pryor, S. C., Räisänen, P., Swietlicki, E., Wiedensohler, A., Worsnop, D. R., Kerminen, V.-M., and Kulmala, M.: Warming-induced increase in aerosol number concentration likely to moderate climate change, Nat. Geosci. Lett., 12, 438-442, 2013.

Patokoski, J., Ruuskanen, T. M., Hellén, H., Taipale, R., Grönholm, T., Kajos, M. K., Petäjä, T., Hakola, H., Kulmala, M., and Rinne, J.: Winter to spring transition and diurnal variation of VOCs in Finland at an urban background site and a rural site, Boreal Environ. Res., 19, 79-103, 2014.

Patoulias, D., Fountoukis, C., Riipinen, I., and Pandis, S. N.: The role of organic condensation on ultrafine particle growth during nucleation events, Atmos. Chem. Phys. Discuss., 14, 3076130798, doi:10.5194/acpd-14-30761-2014, 2014.

Piccot, S. D., Watson, J. J., and Jones, J. W.: A global inventory of volatile organic compound emissions from anthropogenic sources, J. Geophys. Res., 97, 9897-9912, doi:10.1029/92JD00682, 1992.

Plass-Dülmer, C., Schmidbauer, N., Slemr, J., Slemr, F., and D'Souza, H.: European hydrocarbon intercomparison experiment AMOHA part 4: canister sampling of ambient air, J. Geophys. Res., 111, D04306, doi:10.1029/2005JD006351, 2006.

Rantala, P., Taipale, R., Aalto, J., Kajos, M. K., Patokoski, J., Ruuskanen, T. M., and Rinne, J.: Continuous flux measurements of VOCs using PTR-MS - reliability and feasibility of disjunct-eddy-covariance, surface-layer-gradient, and surfacelayer-profile methods, Boreal Environ. Res., 19, 87-107, 2014.

Rantala, P., Aalto, J., Taipale, R., Ruuskanen, T. M., and Rinne, J.: Annual cycle of volatile organic compound exchange between 
a boreal pine forest and the atmosphere, Biogeosciences, 12, 5753-5770, doi:10.5194/bg-12-5753-2015, 2015.

Rappenglück, B., Apel, E., Bauerfeind, M., Bottenheim, J., Brickell, P., Čavolka, P., Cech, J., Gatti, L., Hakola, H., Honzak, J., Junek, R., Martin, D., Noone, C., Plass-Dülmer, C., Travers, D., and Wang, D.: The first VOC intercomparison exercise within the Global Atmosphere Watch (GAW), Atmos. Environ., 40, 75087527, 2006.

Riipinen, I., Yli-Juuti, T., Pierce, J. R., Petäjä, T., Worsnop, D. R., Kulmala, M., and Donahue, N. M.: The contribution of organics to atmospheric nanoparticle growth, Nat. Geosci., 5, 453-458, 2012.

Rinne, J., Ruuskanen, T. M., Reissell, A., Taipale, R., Hakola, H., Kulmala, M., and Kulmala, M.: On-line PTR-MS measurements of atmospheric concentrations of volatile organic compounds in a European boreal forest ecosystem, Boreal Environ. Res., 10, 425-436, 2005.

Rinne, J., Taipale, R., Markkanen, T., Ruuskanen, T. M., Hellén, H., Kajos, M. K., Vesala, T., and Kulmala, M.: Hydrocarbon fluxes above a Scots pine forest canopy: measurements and modeling, Atmos. Chem. Phys., 7, 3361-3372, doi:10.5194/acp-7-33612007, 2007.

Rohrer, F., Lu, K., Hofzumahaus, A., Bohn, B., Brauers, T., Chang, C., Fuchs, H., Haseler, R., Holland, F., Hu, M., Kita, K., Kondo, Y., Li, X., Lou, S., Oebel, A., Shao, M., Zeng, L., Zhu, T., Zhang, Y., and Wahner, A.: Maximum efficiency in the hydroxylradical-based self-cleansing of the troposphere, Nat. Geosci., 7, 559-563, doi:10.1038/ngeo2199, 2014.

Sauvage, S., Plaisance, H., Locoge, N., Wroblewski, A., Coddeville, P., and Galloo, J.: Long term measurement and source apportionment of non-methane hydrocarbons in three French rural areas, Atmos. Environ., 43, 2430-2441, doi:10.1016/j.atmosenv.2009.02.001, 2009.

Slemr, J., Slemr, F., Partridge, R., D’Souza, H., and Schmidbauer, N.: Accurate Measurements of Hydrocarbons in the Atmosphere (AMOHA): three European intercomparisons, J. Geophys. Res., 107, 4409, doi:10.1029/2001JD001357, 2002.

Smolander, S., He, Q., Mogensen, D., Zhou, L., Bäck, J., Ruuskanen, T., Noe, S., Guenther, A., Aaltonen, H., Kulmala, M., and Boy, M.: Comparing three vegetation monoterpene emission models to measured gas concentrations with a model of meteorology, air chemistry and chemical transport, Biogeosciences, 11, 5425-5443, doi:10.5194/bg-11-5425-2014, 2014.

Steinbacher, M., Dommen, J., Ammann, C., Spirig, C., Neftel, A., and Prevot, A.: Performance characteristics of a proton-transferreaction mass spectrometer (PTR-MS) derived from laboratory and field measurements, Int. J. Mass Spectrom., 239, 117-128, doi:10.1016/j.ijms.2004.07.015, 2004.
Taipale, R., Ruuskanen, T. M., Rinne, J., Kajos, M. K., Hakola, H., Pohja, T., and Kulmala, M.: Technical Note: Quantitative longterm measurements of VOC concentrations by PTR-MS - measurement, calibration, and volume mixing ratio calculation methods, Atmos. Chem. Phys., 8, 6681-6698, doi:10.5194/acp-86681-2008, 2008.

Tani, A., Hayward, S., and Hewitt, C. N.: Measurement of monoterpenes and related compounds by proton transfer reaction-mass spectrometry (PTR-MS), Int. J. Mass Spectrom., 223-224, 561578, doi:10.1016/S1387-3806(02)00880-1, 2003.

Tunved, P., Hansson, H.-C., Kerminen, V.-M., Ström, J., Dal Maso, M., Lihavainen, H., Viisanen, Y., Aalto, P. P., Komppula, M., and Kulmala, M.: High natural aerosol loading over boreal forests, Science, 312, 261-263, 2006.

Villanueva-Fierro, I., Popp, C. J., and Martin, R.: Biogenic emissions and ambient concentrations of hydrocarbons, carbonyl compounds and organic acids from ponderosa pine and cottonwood trees at rural and forested sites in Central New Mexico, Atmos. Environ., 38, 249-260, 2004.

Warneke, C., Kuczynski, J., Hansel, A., Jordan, A., Vogel, W., and Lindinger, W.: Proton transfer reaction mass spectrometry (PTRMS): propanol in human breath, Int. J. Mass Spectrom., 154, 6170, doi:10.1016/0168-1176(96)04369-8, 1996.

Warneke, C., van der Veen, C., Luxembourg, S., de Gouw, J., and Kok, A.: Measurements of benzene and toluene in ambient air using proton-transfer-reaction mass spectrometry: calibration, humidity dependence, and field intercomparison, Int. J. Mass Spectrom., 207, 167-182, doi:10.1016/S1387-3806(01)00366-9, 2001.

Warneke, C., de Gouw, J., Kuster, W., Goldan, P., and Fall, R.: Validation of atmospheric VOC measurements by proton-transferreaction mass spectrometry using a gas-chromatographic preseparation method, Environ. Sci. Technol., 37, 2494-2501, doi:10.1021/es026266i, 2003.

Warneke, C., Veres, P., Murphy, S. M., Soltis, J., Field, R. A., Graus, M. G., Koss, A., Li, S.-M., Li, R., Yuan, B., Roberts, J. M., and de Gouw, J. A.: PTR-QMS versus PTR-TOF comparison in a region with oil and natural gas extraction industry in the Uintah Basin in 2013, Atmos. Meas. Tech., 8, 411-420, doi:10.5194/amt-8-411-2015, 2015. 